\title{
Spatial and temporal variability of clouds and precipitation over Germany: multiscale simulations across the "gray zone"
}

\author{
C. Barthlott and C. Hoose \\ Institute of Meteorology and Climate Research (IMK-TRO), Karlsruhe Institute of Technology (KIT), Karlsruhe, Germany
}

Correspondence to: C. Barthlott (christian.barthlott@kit.edu)

Received: 26 May 2015 - Published in Atmos. Chem. Phys. Discuss.: 24 June 2015

Revised: 16 September 2015 - Accepted: 2 November 2015 - Published: 9 November 2015

\begin{abstract}
This paper assesses the resolution dependance of clouds and precipitation over Germany by numerical simulations with the COnsortium for Small-scale MOdeling (COSMO) model. Six intensive observation periods of the $\mathrm{HOPE}\left(\mathrm{HD}(\mathrm{CP})^{2}\right.$ Observational Prototype Experiment) measurement campaign conducted in spring 2013 and 1 summer day of the same year are simulated. By means of a series of grid-refinement resolution tests (horizontal grid spacing $2.8,1 \mathrm{~km}, 500$, and $250 \mathrm{~m}$ ), the applicability of the COSMO model to represent real weather events in the gray zone, i.e., the scale ranging between the mesoscale limit (no turbulence resolved) and the large-eddy simulation limit (energy-containing turbulence resolved), is tested. To the authors' knowledge, this paper presents the first non-idealized COSMO simulations in the peer-reviewed literature at the $250-500 \mathrm{~m}$ scale. It is found that the kinetic energy spectra derived from model output show the expected $-5 / 3$ slope, as well as a dependency on model resolution, and that the effective resolution lies between 6 and 7 times the nominal resolution. Although the representation of a number of processes is enhanced with resolution (e.g., boundary-layer thermals, low-level convergence zones, gravity waves), their influence on the temporal evolution of precipitation is rather weak. However, rain intensities vary with resolution, leading to differences in the total rain amount of up to $+48 \%$. Furthermore, the location of rain is similar for the springtime cases with moderate and strong synoptic forcing, whereas significant differences are obtained for the summertime case with air mass convection. Domain-averaged liquid water paths and cloud condensate profiles are used to analyze the temporal and spatial variability of the simulated clouds. Finally, probability density functions of convection-related parameters are analyzed to investigate their dependance on model
\end{abstract}

resolution and their impact on cloud formation and subsequent precipitation.

\section{Introduction}

The quantitative forecast of precipitation and clouds is still a challenge for state-of-the-art numerical models on both short-range weather time scales and climate time scales. Although the phenomena responsible for triggering convection are broadly known (Jorgensen and Weckwerth, 2003; Bennett et al., 2006), the forecasting skill especially for heavy convective showers is still low. A large part of the inaccuracy results from the difficulties of the models to initiate cloud formation and convective processes at the right place and time (e.g., Barthlott et al., 2011). Besides uncertain initial and boundary conditions, inaccuracies of numerical methods and/or the incomplete description of physical processes influence the performance of the numerical models. The successful simulation of convection initiation over land, which is strongly forced from the surface, depends on having a reasonable representation of boundary-layer processes and the development of shallow cumulus convection (e.g., Petch et al., 2002). Some of the boundary-layer circulations, such as convective rolls, drylines, gust fronts, orographic circulations, and circulations resulting from mesoscale surface heterogeneities (i.e., land use, soil moisture), are precursors of cloud formation and convective development (Jorgensen and Weckwerth, 2003).

To improve our understanding of cloud and precipitation processes and their implication for climate prediction, the High Definition Clouds and Precipitation for advancing Climate Prediction $\mathrm{HD}(\mathrm{CP})^{2}$ research project has 
started (http://hdcp2.eu). $\mathrm{HD}(\mathrm{CP})^{2}$ is a Germany-wide initiative funded by the Federal Ministry of Education and Research (BMBF). Besides the development of a new model system capable of conducting very-high-resolution simulations over domains of $1000 \mathrm{~km}$, a fundamental part of the project was a large measurement campaign entitled HOPE $\left(\mathrm{HD}(\mathrm{CP})^{2}\right.$ Observational Prototype Experiment). HOPE was conducted in spring 2013 near Jülich in western Germany and included a large variety of in situ and remote sensing instruments. Based on these measurements, the model can be evaluated critically on the scale of the model simulations and information is obtained on subgrid-scale variability and microphysical properties that are subject to parameterizations. A major observation system operated during HOPE was the so-called KITcube (Kalthoff et al., 2013), which is a monitoring system consisting of different in situ and remote sensing instruments.

In smaller-scale meteorological applications, two classes of numerical modeling are distinguished: mesoscale modeling on larger domains and large-eddy simulations (LES) on the smaller ones (Wyngaard, 2004). The ratio of the energy-containing turbulence scale and the scale of the spatial filter used in the equations of motion $l / \Delta$ is small for mesoscale modeling (no turbulence resolved) and large for LES (energy-containing turbulence is resolved). With increasing computer power in the last years, it is now possible to conduct very finely meshed simulations with $l / \Delta \sim 1$. Since neither LES nor mesoscale models were designed to operate in this range, it was called "terra incognita" or "gray zone" (Wyngaard, 2004). For the $\mathrm{HD}(\mathrm{CP})^{2}$ project, it was decided to jump over this gray zone with the development of a new model system ICON (ICOsahedral Non-hydrostatic; Zängl et al., 2015) which can be operated for domains with $1000 \mathrm{~km} \times 1000 \mathrm{~km}$ at a horizontal grid spacing of $100 \mathrm{~m}$. Since current operational models still operate in this range (e.g., German Weather Service: $2.8 \mathrm{~km}$; UK Met Office: $1.5 \mathrm{~km}$; Meteo France: $2.5 \mathrm{~km}$ ), it is of interest to understand which results can be obtained from simulations within the gray zone in order to assess the impact of grid spacing on quantitative precipitation forecasting.

In recent years, many studies were devoted to exploring the resolution dependance of numerical weather forecasting for different synoptic conditions and geographical areas. The most remarkable feature of numerical models with grid spacing smaller than $2-4 \mathrm{~km}$ is the possibility to explicitly treat deep convection instead of using a parameterization. Many studies have shown that such models provide quantitatively better results in terms of the simulated precipitation amount, its structure, and timing (e.g., Done et al., 2004; Weisman et al., 2008; Bauer et al., 2011). However, small-scale updrafts and the turbulent nature of the flow can only be represented adequately by large-eddy simulations at a grid length of $100 \mathrm{~m}$ or less (Bryan et al., 2003). Thus, the convectionpermitting models operating at the order $\mathrm{O}(1 \mathrm{~km})$ have major shortcomings in regards to the nature of convective clouds (Hanley et al., 2014).

Once convection-permitting resolutions are reached, it remains unclear as to whether increasingly fine horizontal grid spacing alone can result in further increases in forecast skill (e.g., Roebber et al., 2004). Recent findings of Kain et al. (2008) and Schwartz et al. (2009) suggest that decreasing horizontal grid spacing from 4 to $1-2 \mathrm{~km}$ provides little added value and that forecast skill in the USA is not improved. One possible reason may be that more sophisticated physical parameterizations (e.g., for boundary-layer turbulence or cloud microphysics) are needed at such high resolution. However, there are also opposite findings of refining the mesh size having improved the quantitative precipitation forecast results: for example, Zängl (2007) investigated two north-Alpine heavy-rainfall cases with a variable number of nested domains, resulting in finest mesh sizes of 9,3 , and $1 \mathrm{~km}$. The runs with high grid resolutions had a highly beneficial impact in the Alpine part of the area due to a proper representation of the topography. For a case study of a quasi-stationary convective system over the UK Southwest Peninsula, Warren et al. (2014) found several deficiencies in the $1.5 \mathrm{~km}$ model's representation of the storm system. However, significant improvements regarding convection initiation were found when the grid length was reduced to $500 \mathrm{~m}$ due to an improved representation of a convergence line. Hanley et al. (2014) simulated several convective events over the southern UK at horizontal grid lengths ranging from $1.5 \mathrm{~km}$ to $200 \mathrm{~m}$ with the Met Office Unified Model. Their results suggest that convection is under-resolved at a grid length of $1.5 \mathrm{~km}$. Although an improvement in convection initiation time was observed when reducing the grid length, the size and intensity of the cells were not necessarily improved. Furthermore, changing the mixing length often improves one aspect of the simulated convection, while another aspect is affected adversely.

Using the WRF model for simulation of a convection situation over the Black Forest mountains in southwest Germany, Bennett et al. (2011) found that a high resolution of $700 \mathrm{~m}$ was needed to capture the fine-scale motions over the complex terrain for convection to be reproduced at the correct location and with about the right intensity to match the observations. A positive impact of increased model resolution was also found by Colle and Mass (2000) for the Cascade Mountains in the Pacific Northwest of the USA when moving from a grid spacing of 36 to 12 to $4 \mathrm{~km}$. Whereas the high grid spacing was needed to properly resolve terrain forcing, no additional gain was obtained when refining the grid to $1.33 \mathrm{~km}$. For Iceland, Rögnvaldsson et al. (2007) investigated orographic precipitation with 8,4 , and $2 \mathrm{~km}$ horizontal grid spacing. They found that the absolute values and the pattern of the precipitation field were improved in a stepwise manner when increasing the model resolution, with the main increase resulting from the transition from 8 to $4 \mathrm{~km}$. Pearson et al. (2014) showed that the improvement in the repre- 
sentation of the diurnal cycle of convective organization over West Africa by a $4 \mathrm{~km}$ model compared to a $12 \mathrm{~km}$ configuration was a result of the convection scheme rather than the improved resolution.

Whereas most of the above-mentioned studies of resolution dependance of numerical weather forecasting with realistic model configurations were conducted at or above the order $\mathrm{O}(1 \mathrm{~km})$, only a few studies are available for grid lengths ranging between $100 \mathrm{~m}$ and $1 \mathrm{~km}$ : e.g., Boutle et al. (2014) for a case of stratocumulus evolution or Green and Zhang (2015) for a modeling study of Hurricane Katrina. Most of the studies in this range used idealized configurations (e.g., Bryan et al., 2003; Wyngaard, 2004; Fiori et al., 2009, 2011; Verrelle et al., 2015). These previous studies suggest that horizontal resolution may be important when modeling cloud formation and precipitation. However, it remains unclear whether the model features originally designed for the simulation of larger-scale atmospheric flows will yield adequate reproductions of small-scale motions (Gibbs and Fedorovich, 2014). This line of investigation is now extended by numerical simulations of realistic cases with quasi-operational model settings but different model resolutions. As cloud evolution and turbulence still need to be parameterized on that scale, a good representation of subgrid-scale variability is essential. Therefore, the focus of this paper lies not only on the impact of a higher grid spacing on cloud and precipitation development but also on the variability of convection and cloud-related parameters and how this variability changes with model resolution. Instead of analyzing mean values of such parameters, probability distributions show the range of possible values and the most probable ones. To this end, we systematically explore the gray zone and test the applicability of the COnsortium for Small-scale MOdeling (COSMO) model at high resolutions to several cases with different synoptic conditions.

\section{Method}

In order to investigate the potential benefits of a higher grid resolution for the simulation of convective rain, a series of numerical simulations were performed using version 5.0 of the COSMO model. This section describes the model configuration and the days chosen for this study.

\subsection{Numerical model}

The COSMO model is a non-hydrostatic regional weather forecast model (Schättler et al., 2013) used for operational weather forecasting at the Deutscher Wetterdienst (DWD, German Weather Service) and several other European weather services. It employs an Arakawa C-grid for horizontal differencing on a rotated latitude/longitude grid. To minimize problems resulting from the convergence of the meridians, the pole of the grid is rotated such that the equa- tor runs through the center of the model domain. In the vertical direction, a terrain-following, hybrid height coordinate is used. A two-time level Runge-Kutta method (Wicker and Skamarock, 2002) for time integration is implemented. The microphysics scheme includes riming processes (graupel formation) and predicts cloud water, rain water, cloud ice, snow, and graupel. A multi-layer soil vegetation model (TERRAML; Doms et al., 2011) is implemented.

At the DWD, the application COSMO-EU of the COSMO model provides operational forecasts for all of Europe at $7 \mathrm{~km}$ grid spacing with initial and boundary conditions derived from the hydrostatic global model GME (mesh size $40 \mathrm{~km}$ ). Deep and shallow convection are parameterized using a Tiedtke scheme (Tiedtke, 1989) in COSMO-EU. In addition, a convection-permitting version (COSMO-DE) with $2.8 \mathrm{~km}$ grid spacing is used for Germany and smaller parts of neighboring countries. The horizontal grid spacing of $2.8 \mathrm{~km}$ allows the parameterization of deep convection to be switched off. Small-scale shallow convection is parameterized using a modified Tiedtke scheme. According to Baldauf et al. (2011), the operational COSMO-DE produces satisfactory results in synoptically driven situations, but the model (as many other operational models, too) still has problems correctly describing convection initiation at the right time and place in air mass convection situations.

In this study, numerical simulations with horizontal grid spacings of $2.8 \mathrm{~km}, 1 \mathrm{~km}, 500 \mathrm{~m}$, and $250 \mathrm{~m}$ have been conducted (Table 1). The run with $2.8 \mathrm{~km}$ resolution corresponds to the operational setup used by the DWD and serves as the reference run in this study. Note that also the number of vertical levels is increased for the $1 \mathrm{~km}$ runs and the 500/250 m runs. This limits somehow the conclusions of this study, because the results are affected by both horizontal and vertical grid spacing. However, when moving to finer-resolution simulations, it is also meaningful to increase the number of vertical levels. In doing so, especially the representation of processes in the planetary boundary layer (PBL) and the entrainment zone is supposed to be enhanced. The number of levels in the lowest $1000 \mathrm{~m}$ is 12,15 , and 18 for the runs with 50,65 , and 80 levels, respectively.

At a grid length of $2.8 \mathrm{~km}$, a 1-D turbulence scheme is applied. This 1-D closure is based on a prognostic equation for the turbulent kinetic energy and can be classified as MellorYamada level 2.5 (Mellor and Yamada, 1974), i.e., the stability functions are explicitly predicted. By imposing horizontal homogeneity of the variables, this 1-D closure uses the so-called boundary-layer approximation. For resolutions reaching the kilometer scale and LES, a more adequate 3-D turbulence parameterization can be chosen. This closure uses a 3-D subgrid-scale model instead of the boundary-layer approximation and both vertical and horizontal turbulent coefficients are active (Doms et al., 2011). At a grid length of $1 \mathrm{~km}$, it is still unclear what scheme should be used. As was demonstrated by Wyngaard (2004) and Honnert et al. (2011), the use of a 1-D turbulence scheme remains questionable on 
Table 1. Model configuration details.

\begin{tabular}{lrrrrrr}
\hline Name & $\begin{array}{r}\text { Grid spacing } \\
(\mathrm{km})\end{array}$ & $\begin{array}{r}\text { No. horiz. } \\
\text { grid points }\end{array}$ & $\begin{array}{r}\text { No. vert. } \\
\text { levels }\end{array}$ & $\begin{array}{r}\text { Time step } \\
(\mathrm{s})\end{array}$ & $\begin{array}{l}\text { Shallow } \\
\text { convection }\end{array}$ & $\begin{array}{l}\text { Turbulence } \\
\text { scheme }\end{array}$ \\
\hline C2.8 (reference run) & 2.8 & $421 \times 461$ & 50 & 25 & parameterized & 1-D \\
C1-1D & 1 & $780 \times 800$ & 65 & 2 & parameterized & 1-D \\
C1-3D & 1 & $780 \times 800$ & 65 & 2 & parameterized & $3-\mathrm{D}$ \\
C0.5 & 0.5 & $1200 \times 1500$ & 80 & 2 & resolved & 3-D \\
C0.25 & 0.25 & $1500 \times 2250$ & 80 & 2 & resolved & 3-D \\
\hline
\end{tabular}

this scale, while the formulation used in LES may not be appropriate. Therefore, the $1 \mathrm{~km}$ model was run with both a 1-D and a 3-D turbulence scheme. For the finer resolutions of 500 and $250 \mathrm{~m}$, only the 3-D turbulence scheme was applied. For the 500 and $250 \mathrm{~m}$ runs, the parameterization of shallow convection is switched off whereas the runs with coarser resolution still need this parameterization to be active to adequately simulate the moisture transport from the surface to the cloud layer (Tiedtke, 1989; Doms et al., 2011).

The $2.8 \mathrm{~km}$ runs used a time step of $25 \mathrm{~s}$, whereas all other runs used a value of $2 \mathrm{~s}$. This large reduction in the time step was necessary to prevent numerical problems and model instabilities over steep orography. COSMO-EU analyses serve as initial and boundary conditions for the reference run, whose outcome is then used to drive all of the higher-resolution simulations. Since no suite of nesting is performed and the same driving data are used for the resolution below $2.8 \mathrm{~km}$, the interpretation of the numerical results is facilitated. In a sensitivity experiment (not shown), a suite of nested domains was used, but the results differed only marginally from those of the above configuration. The lateral boundary update interval is $1 \mathrm{~h}(2.8 \mathrm{~km}$ grid spacing $)$ and $15 \mathrm{~min}$ for the remaining model runs. The smaller interval is due to the smaller model domain which makes it necessary to prevent showers (or large-scale phenomena) persisting for a long time at the edges of the model domain. All model runs do not include data assimilation or feedbacks between individual nests. Each model run is initialized at 00:00 UTC with an integration time of $24 \mathrm{~h}$.

The simulation domain (Fig. 1) of the reference run is identical to the COSMO-DE operational configuration. It is aimed at using the largest possible domain for the highresolution simulations, but numerical problems for very steep orography and the required data storage capacities and computing time lead to smaller simulation domains as model resolution increases. For the analysis presented later, a common domain was chosen to be somewhat smaller than the $250 \mathrm{~m}$ run to prevent edge effects (black rectangle in Fig. 1).

An important feature of our simulations is the fact that we use the same external data (orography, soil type, land use) for all model runs. The external data are based on $30 \operatorname{arcsec}(1 \mathrm{~km})$ gridded, quality-controlled Global Land One-km Base Elevation Project (GLOBE) orography, the

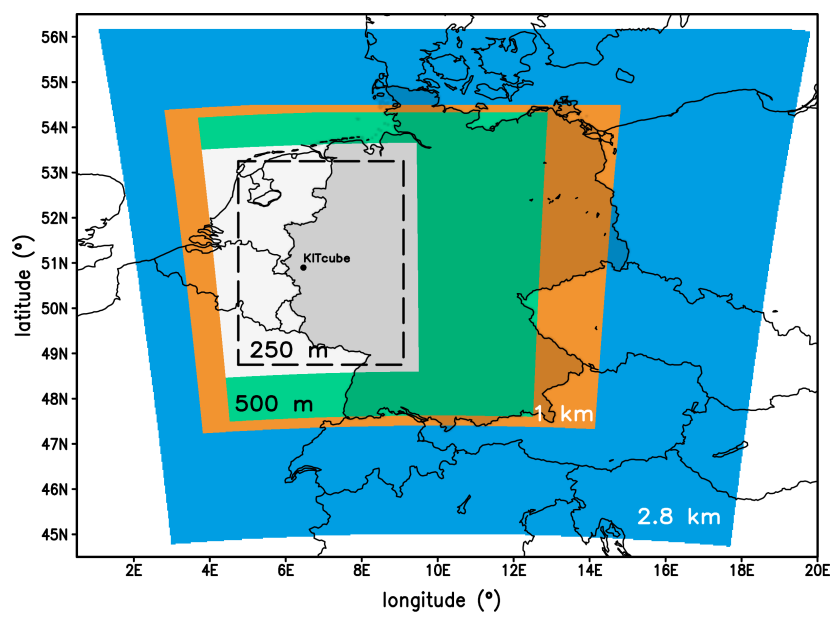

Figure 1. Simulation domains. The dashed rectangle indicates the common investigation area used in this study. The measurement area of the HOPE field campaign is located around the KITcube position.

Global Land Cover 2000 Project (GLC 2000) for a harmonized land cover, and the Food and Agriculture Organization of the United Nations (FAO) Digital Soil Map of the World (DSMW). This data set was interpolated on the respective model grids with an internal consistency check. This means that all changes in the simulation results are a response to a different model resolution only and are not linked to a better representation of the underlying orography and land data. The model orography in the $2.8 \mathrm{~km}$ configuration smoothes out some of the orographic features (like smaller valleys) visible at $1 \mathrm{~km}$ resolution and also maximum elevations of individual mountain ridges are lower compared to the $1 \mathrm{~km}$ data (not shown). When interpolating to the 500 and $250 \mathrm{~m}$ grids, the orographic features of the $1 \mathrm{~km}$ data stay the same, with the exception of minor interpolation artifacts at the coastline.

\subsection{Cases analyzed}

This study considers six cases from the HOPE field campaign with different weather characteristics (dry and moist convection, varying degree of synoptic forcing). As the field campaign took place in spring, there was no summertime event with local initiation of deep convection. To also consider this 
Table 2. Weather characteristics at the HOPE measurement site for the intensive observation periods (IOP) used in this study. "n/a" means not applicable.

\begin{tabular}{ll}
\hline Day (IOP) & Weather characteristics \\
\hline $\begin{array}{l}\text { 15 April } \\
\text { IOP 3) }\end{array}$ & $\begin{array}{l}\text { broken cumulus cloudiness in the morning, overcast during noon (11:00-16:00 UTC) with light } \\
\text { rain, clearance in the evening, weak wind }\end{array}$ \\
\hline $\begin{array}{l}\text { 24 April } \\
\text { (IOP 6) }\end{array}$ & clear-sky day with only few cirrus clouds in the morning and afternoon, weak southerly winds \\
\hline $\begin{array}{l}\text { 25 April } \\
\text { (IOP 7) }\end{array}$ & $\begin{array}{l}\text { cloudy morning (up to 4/8) until 10:00 UTC, only a few clouds during noon, afterwards again } \\
\text { increasing cumulus humilis cloudiness, wind turns from south to west in the afternoon }\end{array}$ \\
\hline $\begin{array}{l}\text { 26 April } \\
\text { IOP 8) }\end{array}$ & $\begin{array}{l}\text { rapidly increasing cloudiness up to complete overcast situation until noon, several rain showers } \\
\text { and light to medium rain, decreasing cloudiness in the late afternoon, quickly turning wind from } \\
\text { south to north during midday due to front passage, decreasing temperatures }\end{array}$ \\
\hline $\begin{array}{l}\text { 19 May } \\
\text { (IOP 14) }\end{array}$ & $\begin{array}{l}\text { fog in the morning, afterwards clear-sky conditions until late afternoon, only very few low } \\
\text { cumulus humilis clouds, rising cirrus clouds in the afternoon to evening, wind from north }\end{array}$ \\
\hline $\begin{array}{l}\text { 28 May } \\
\text { (IOP 18) }\end{array}$ & $\begin{array}{l}\text { clear-sky conditions until midday (10:00 UTC) with only very few cirrus clouds, following low } \\
\text { cumulus humilis clouds until 17:00 UTC, afterwards rapidly increasing cloudiness with rain } \\
\text { starting in the evening, wind turns from south to east }\end{array}$ \\
\hline $\begin{array}{l}\text { 23 July } \\
\text { (n/a) }\end{array}$ & $\begin{array}{l}\text { decaying convective showers during night, afterwards clear-sky conditions, after 12:00 UTC } \\
\text { widespread initiation of deep convection }\end{array}$ \\
\hline
\end{tabular}

type of event, simulations were performed for a summer case with air mass convection (see Table 2).

For the description of the synoptic situation of the selected days, we use the $Q$ vector at $500 \mathrm{hPa}$ :

$$
\boldsymbol{Q}=-\frac{R}{p}\left(\frac{\partial \boldsymbol{v}_{\mathrm{g}}}{\partial x} \cdot \nabla T, \frac{\partial \boldsymbol{v}_{\mathrm{g}}}{\partial y} \cdot \nabla T\right),
$$

where $R$ is the gas constant of dry air, $p$ is pressure, $\boldsymbol{v}_{\mathrm{g}}$ is the geostrophic wind, and $T$ is temperature (Hoskins et al., 1978). Areas with forcing for upward (downward) vertical motion are associated with $\boldsymbol{Q}$ vector convergence (divergence). In our study, the $\boldsymbol{Q}$ vector is estimated from $7 \mathrm{~km}$ COSMO-EU analyses which also serve as initial and boundary condition for our simulations. Figure 2 shows the synoptic conditions of the selected days at 12:00 UTC. On 15 April (Fig. 2a), a weak southwesterly flow is present with only weak $\boldsymbol{Q}$ vector convergence. A ridge over southeastern Germany inhibits convective processes in that area. Over western and northwestern Germany, however, radar-derived measurements show widespread moderate amounts of rain with up to $10-15 \mathrm{~mm}$ (Fig. 3a). The conditions on 24 and 25 April (Fig. 2b and c) are similar: a moderate westerly flow together with only small forcing for upward and downward motion. On both days, no precipitation is measured near the KITcube location. Only small amounts of rain are observed in the northern part of the investigation area on 25 April (Fig. 3b). The mid-tropospheric flow intensifies on the next day (26 April, Fig. 2d) with the flow direction turning to southwest. On this day, radar measurements indicate pre- cipitation almost over entire Germany with $24 \mathrm{~h}$ accumulations of up to $30 \mathrm{~mm}$ (Fig. 3c). The maximum, but still small, rain amounts are observed to the north and south of the KITcube location. On 19 May (Fig. 2e), two low-pressure regions influence Germany, one of them being located north of Poland and the other over central France. The HOPE measurement site is located at the northern edge of the low over France with weak easterly winds. In the southern part of Germany, spatially widespread precipitation is observed with peaks of $90 \mathrm{~mm}$, whereas the measurement site is free of rain (Fig. 3d). A long-wave trough extending from Iceland towards northwestern France leads to a southerly flow on 28 May (Fig. 2f). There are convective showers over southern Germany and eastern France as well as moderate rain over the HOPE domain (Fig. 3e). The last day of the cases analyzed (23 July, Fig. 2g) shows a strong ridge over western Germany and eastern France. Despite the convectioninhibiting effect of subsidence, several isolated convective showers are initiated in that area (Fig. 3f).

\section{Model results}

In the following, we first describe some benefits of highresolution modeling before the simulated precipitation is analyzed with respect to location, amount, and timing. The analysis of probability density functions of convectionrelated parameters together with their dominant values and a more detailed case study of one simulated convective cell at high resolution concludes our investigations. 

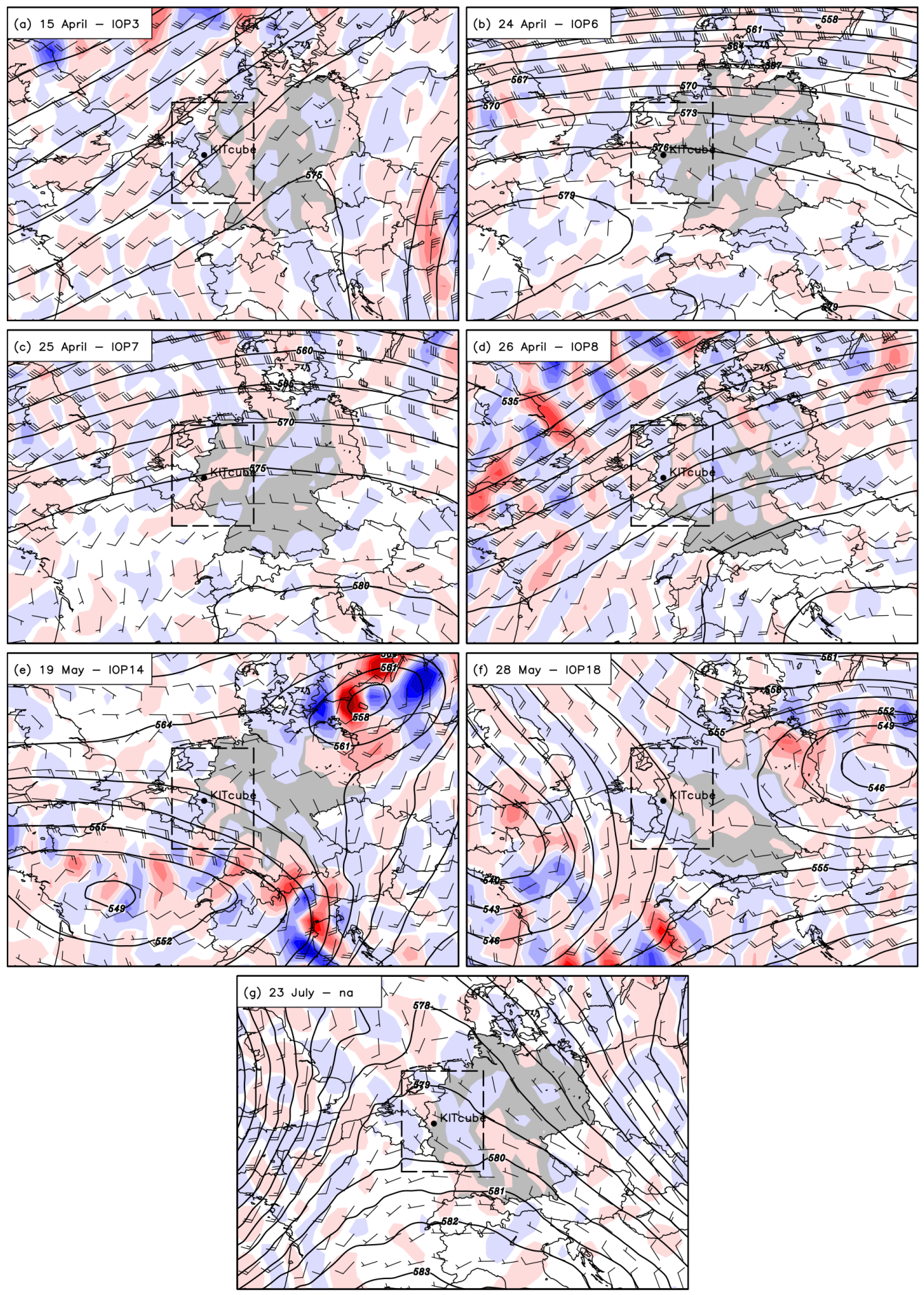

Figure 2. COSMO-EU analyses for 12:00 UTC showing $500 \mathrm{hPa}$ geopotential height (gpdm, contours), $\boldsymbol{Q}$ vector divergence $\left(10^{-17} \mathrm{~m}(\mathrm{~kg} \mathrm{~s})^{-1}\right.$, shading), and horizontal wind (knots). Red colors indicate forcing for upward motion and blue colors for downward motion. The dashed black rectangle indicates the common investigation area. 

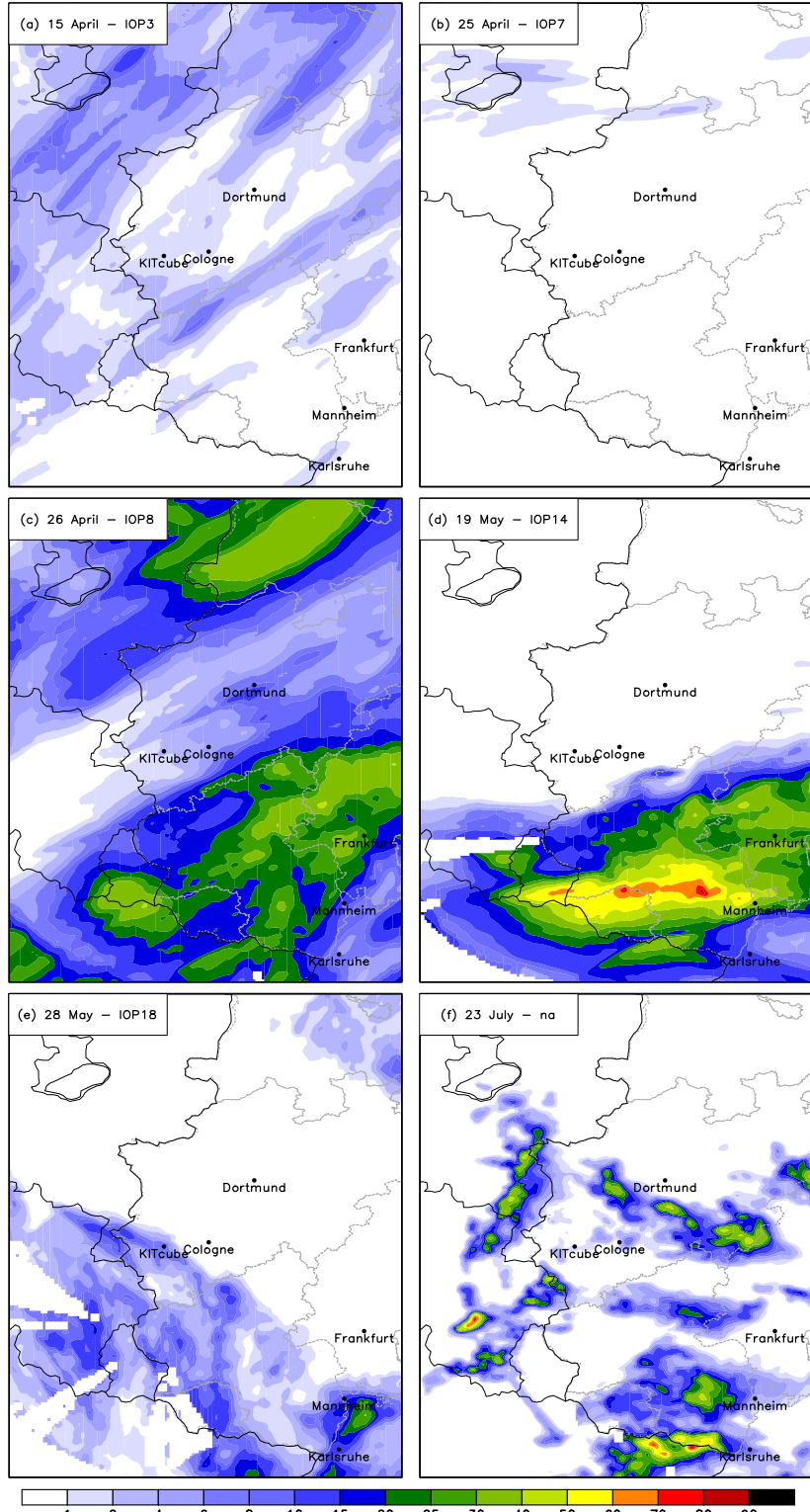

Figure 3. Precipitation amount over $24 \mathrm{~h}$, derived from radar measurements (interpolated to the operational COSMO-DE model grid with $2.8 \mathrm{~km}$ horizontal grid spacing) for the analyzed days. The area shown is the common investigation area already depicted in Fig. 1. Note that 24 April is not shown due to the lack of observed precipitation.

\subsection{Benefits of high-resolution modeling for gravity waves, low-level wind convergence, and $\mathrm{PBL}$ thermals}

In this section, the benefits of high-resolution modeling in simulating atmospheric processes is demonstrated by the analysis of gravity waves, low-level convergence zones, and PBL thermals. As the results concerning these features are very similar in both $1 \mathrm{~km}$ runs (with either 1-D or 3-D tur-
Table 3. Characteristics of low-level wind convergence on 15 April 2013 at 16:00 UTC in $10^{-3} \mathrm{~s}^{-1}$.

\begin{tabular}{lrrr}
\hline Name & Mean & 95th percentile & Maximum \\
\hline C2.8 & 0.18 & 0.50 & 1.42 \\
C1-1D & 0.39 & 1.16 & 3.68 \\
C0.5 & 0.59 & 1.69 & 6.71 \\
C0.25 & 1.01 & 2.83 & 11.15 \\
\hline
\end{tabular}

bulence scheme), we only show the outcome of the run with 1-D scheme. Figure 4 presents a comparison of the simulated vertical velocities at $2.9 \mathrm{~km}$ a.s.l. for 26 April 2013 for the different horizontal grid spacings used. Obviously, the C2.8 run cannot resolve any gravity wave activity on that day. With a grid spacing of $1 \mathrm{~km}$ or below, however, gravity waves are simulated in the southern part of the investigation area. The location of the waves over the mountainous terrain indicates that these waves are induced by orographic lifting of air masses in the presence of stable temperature stratification. Although more fine-scale structures can be seen with even higher resolution $(500,250 \mathrm{~m})$, the locations of the individual regions with upward and downward vertical motion and, thus, the wavelength of the waves (ranging between 11 and $13 \mathrm{~km}$ ) remains identical. The intensity of the vertical motions, however, increases slightly with model resolution. On this day, satellite pictures document the existence of gravity waves with similar wave lengths and extents in that area (not shown). Due to the fact that the locations of the waves are similar in the high-resolution runs and the intensity increases only slightly with model resolution, it can be stated that a horizontal grid spacing of $1 \mathrm{~km}$ should be sufficient for capturing the general characteristics of atmospheric gravity waves at least for the locations and meteorological conditions studied in this paper.

The second meteorological phenomenon analyzed here is the convergence of the low-level wind, which is an important mechanism for convection initiation (e.g., Byers and Rodebush, 1948; Wilson and Schreiber, 1986; Barthlott et al., 2006). To illustrate the resolution dependance of convergence zones, we use 15 April at 16:00 UTC (Fig. 5). Here, we refer to convergence by multiplying the divergence of the horizontal $10 \mathrm{~m}$ wind field by -1 . When doing this, convergent areas leading to lifting of air parcels have a positive sign. The $2.8 \mathrm{~km}$ run reveals only comparatively small regions with weak convergence. At $1 \mathrm{~km}$ grid spacing, there already is a large number of convergent areas: many isolated patches with convergence as well as elongated convergence lines are visible. When going to $500 \mathrm{~m}$ grid spacing, there are more small-scale convergence structures and the elongated zones are more connected. At $250 \mathrm{~m}$ grid spacing, the percentage area of convergent grid points of all model runs is largest $(46 \%)$, whereas the remaining runs show slightly smaller values ranging between 42 and $44 \%$. The location 


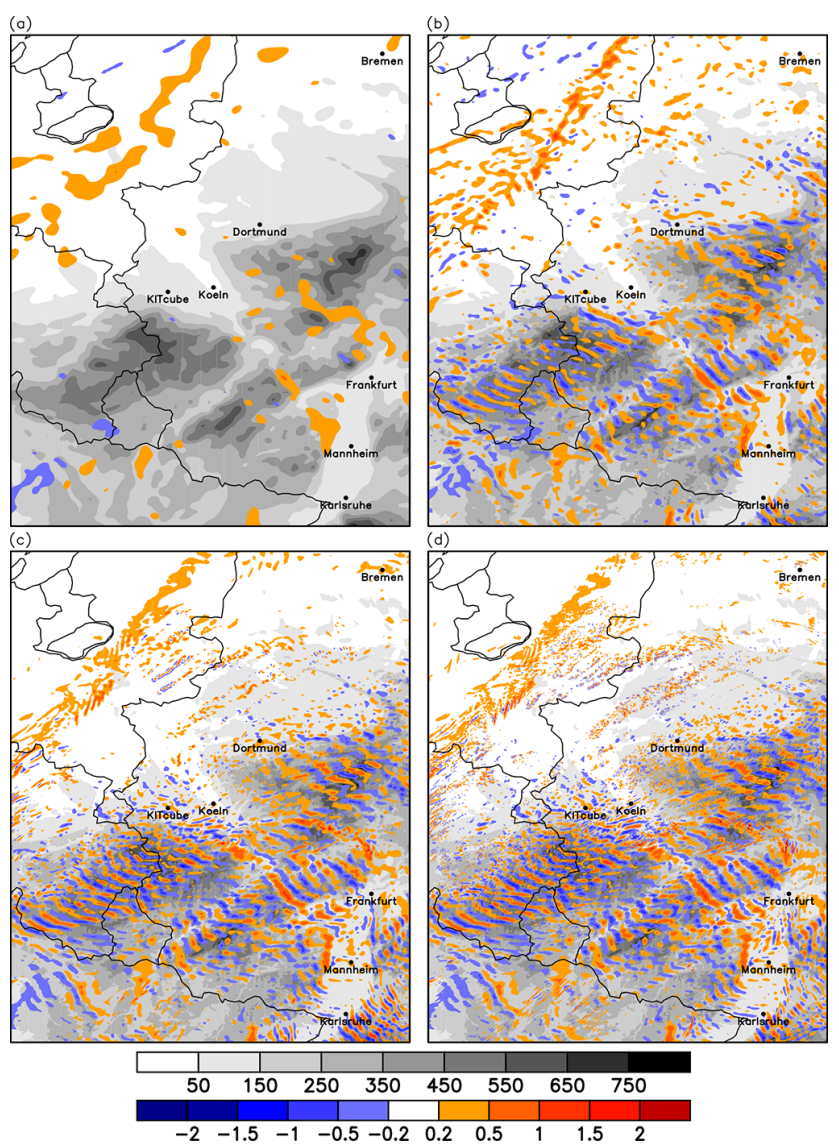

Figure 4. Vertical wind (color shading in $\mathrm{m} \mathrm{s}^{-1}$ at $2900 \mathrm{~m}$ a.s.l. on 26 April 2013 at 11:30 UTC for (a) $2.8 \mathrm{~km}$, (b) $1 \mathrm{~km}$ with 1-D turbulence, (c) $500 \mathrm{~m}$, and (d) $250 \mathrm{~m}$ grid spacing. Gray shading represents model orography in $\mathrm{m}$.

of the areas with the strongest convergence is rather insensitive to model resolution, since there are only minor spatial differences. Besides the increasing ratio of grid points with convergence, the mean value of convergence (only positive contributions), the 95th percentile, and the maximum convergence do increase with grid spacing (Table 3). The increased convergence intensity has important implications for convection initiation due to reduced entrainment (e.g., Garcia-Carreras et al., 2011) and stronger lifting which may allow rising parcels to attain their level of free convection. It is also worth mentioning that there is an area almost free of convergence ranging from Köln towards Bremen. This zone is simulated in all model runs and is associated with a calm post-frontal region. With increasing grid spacing, however, this area is continuously reduced in size.

25 April is chosen to examine the evolution of boundarylayer thermals, because the region of interest is cloudless around noon. Figure 6 presents vertical cross sections of vertical wind and equivalent potential temperature at the latitude of the KITcube location during HOPE (see Fig. 1). Due to the coarse resolution of the $2.8 \mathrm{~km}$ run, no PBL thermals can
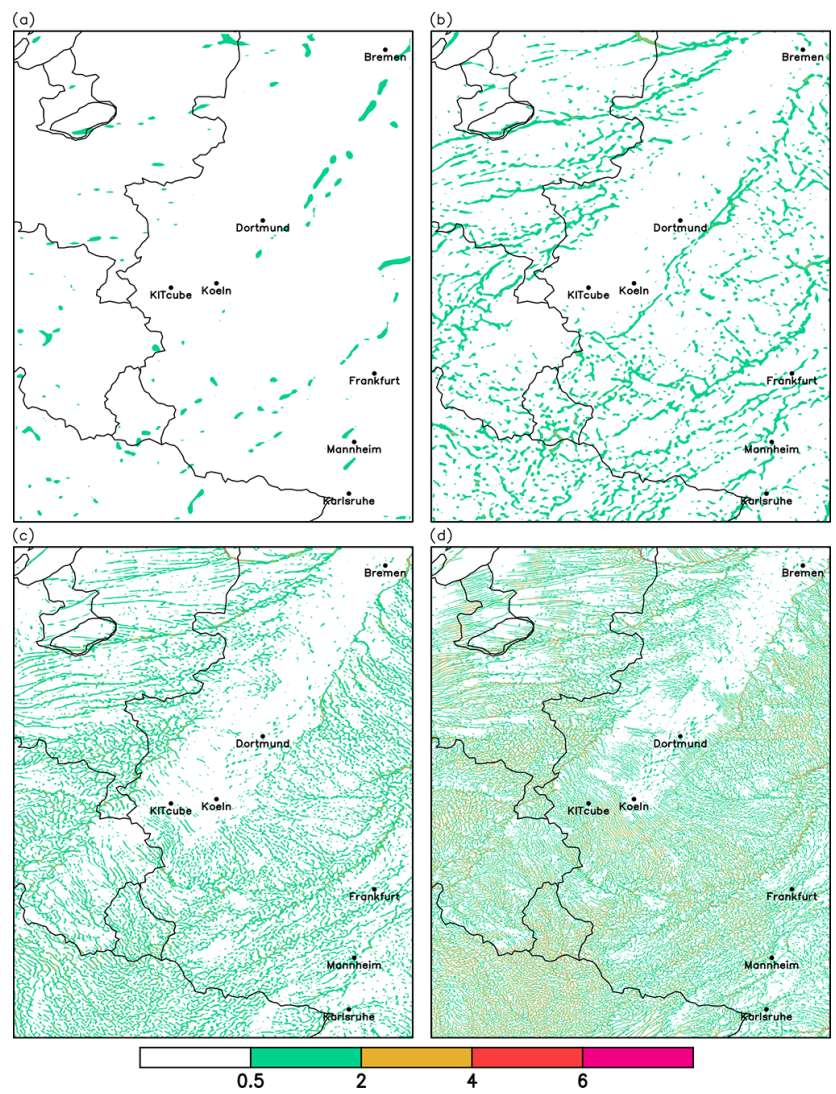

Figure 5. $10 \mathrm{~m}$ wind convergence (shading in $10^{-3} \mathrm{~s}^{-1}$ ) on 15 April 2013 at 16:00 UTC for (a) $2.8 \mathrm{~km}$, (b) $1 \mathrm{~km}$ with 1-D turbulence, (c) $500 \mathrm{~m}$, and (d) $250 \mathrm{~m}$ grid spacing.

be simulated by this configuration. The $1 \mathrm{~km}$ run marginally resolves convective updrafts with vertical velocities larger than $0.2 \mathrm{~m} \mathrm{~s}^{-1}$. When the grid spacing is further reduced, the width of updrafts decreases and the number of updrafts increases to a value of 13 at $250 \mathrm{~m}$ grid spacing. With the horizontal distance from this cross section (approx. $53 \mathrm{~km}$ ), the mean updraft spacing at $250 \mathrm{~m}$ resolution is $4 \mathrm{~km}$. Lidar measurements during HOPE detected updrafts with wavelengths of $2-2.7 \mathrm{~km}$ (V. Maurer et al., personal communication, 2015). On average, the simulated updrafts agree well with these observed values. Furthermore, the narrower updrafts at high resolution exhibit higher vertical velocities in agreement with findings of, e.g., Cotton et al. (2011). As the 500 and $250 \mathrm{~m}$ simulations do not converge to a single solution, there is a need for a even higher model resolution. We would like to point out that the selection of this date and time was based on conditions with more or less undisturbed solar radiation only. The vertical velocity statistics of updraft and downdraft cores are beyond the scope of this paper. 

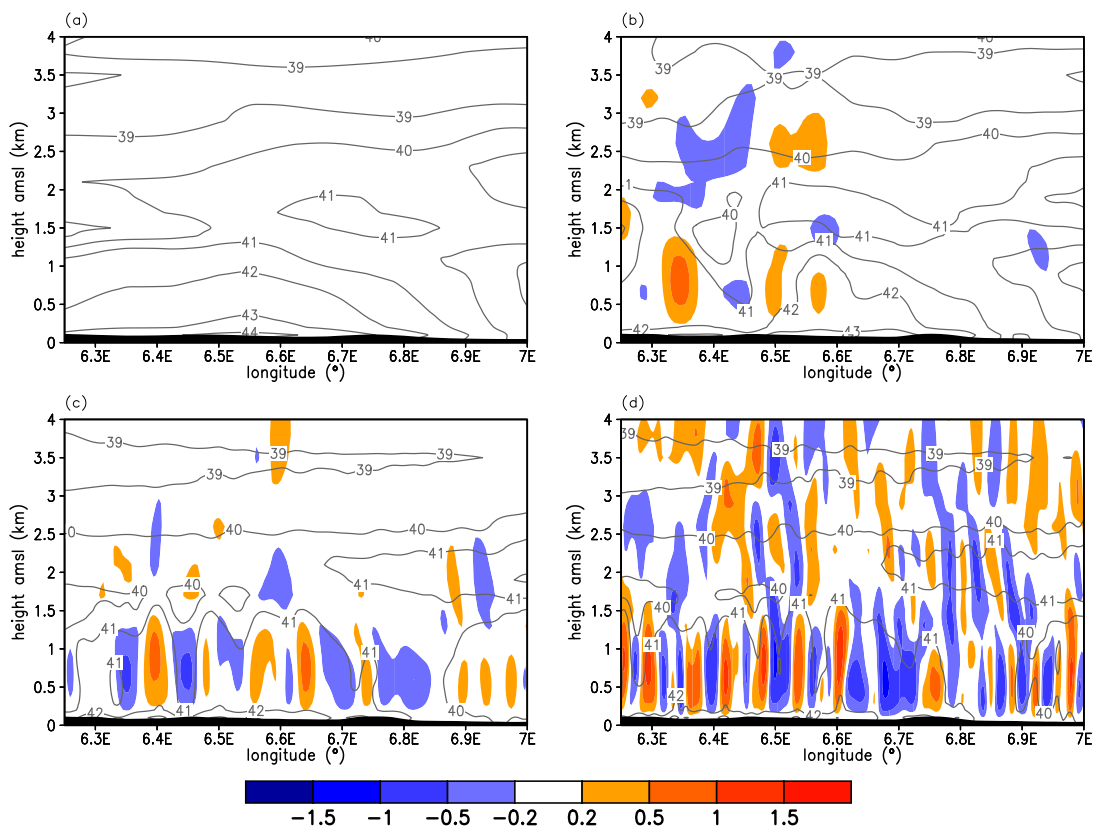

Figure 6. Vertical cross sections of vertical wind speed (shading, in $\mathrm{m} \mathrm{s}^{-1}$ ) and equivalent potential temperature (gray contours in ${ }^{\circ} \mathrm{C}$ ) at the latitude of the KITcube location on 25 April 2013 at 12:00 UTC for (a) $2.8 \mathrm{~km}$, (b) $1 \mathrm{~km}$ with 1-D turbulence, (c) $500 \mathrm{~m}$, and (d) $250 \mathrm{~m}$ grid spacing.

\subsection{Effective model resolution}

The previous section demonstrated that an increased model resolution leads to a better representation of a variety of meteorological processes. To determine whether the parameterizations used for the different model runs are valid at their applied resolution, we computed kinetic energy density spectra from model output in a similar way as proposed by Skamarock (2004): at first, 1-D spectra of the three velocity components were computed along west-east horizontal grid lines in the entire common investigation area. The energy densities were then averaged horizontally by averaging the westeast grid lines over the north-south extent of the area. Finally, the energy densities were time averaged from 10:00 to $24: 00 \mathrm{UTC}$ (at $30 \mathrm{~min}$ intervals) to cover a statistically long enough time period. The late start time of 10:00 UTC was chosen to avoid model spin-up effects. This procedure was done for three heights $(3,5$, and $7 \mathrm{~km}$ a.m.s.l.). As the results do not show any significant differences in terms of shape of the spectra, we show the result for 23 July 2013 in Fig. 7 at $5 \mathrm{~km}$ a.m.s.l. only. It can be seen that the amplitude and wavelength of the energy spectra systematically vary with model resolution: similar to findings from Bryan et al. (2003), the magnitude increases with increasing model resolution and the spectra cover a wider (i.e., more smallscale) range of wavelengths. However, the high-frequency end of the spectra shows white noise only. For all model resolutions, the spectra show a region with a $-5 / 3$ decay in the mesoscale. This region reaches to higher wave num- bers (shorter wavelengths) when model grid spacing is reduced. The point where the gradients (in log space) of the individual spectra decrease below $-5 / 3$ determines the effective resolution of the model. Previous studies have suggested that this occurs at length scales between 6 and 7 times the horizontal grid spacing (e.g., Bryan et al., 2003; Skamarock, 2004; Petrik, 2012). Our simulations show the same behavior; the gradient of the spectra decreases below $-5 / 3$ between 6 and $7 \Delta x$ (marked by the gray shaded areas). Another feature evident here is that the runs with $250 \mathrm{~m}$ grid spacing possess a region with slightly increased energy density (when compared to the $-5 / 3$ slope) before reaching the point of the effective resolution. This might be explained by energy from shorter wavelengths aliased to longer wavelengths (Skamarock, 2004).

\section{3 $24 \mathrm{~h}$ precipitation amount}

In this section, we analyze the $24 \mathrm{~h}$ accumulated precipitations of the numerical simulations (Fig. 8) and compare them with radar-derived precipitation (Fig. 3). Since the focus of this paper is on investigating the resolution dependance of cloud and precipitation-related processes, a qualitative comparison is made only and no quantitative verification methods are applied.

The simulations for 15 April (Fig. 8 top row) show southwest-northeast oriented precipitation bands with maxima between 15 and $20 \mathrm{~mm}$. The precipitation location is very similar in all model runs. In the center of the investigation area (marked by the black rectangle), however, some 


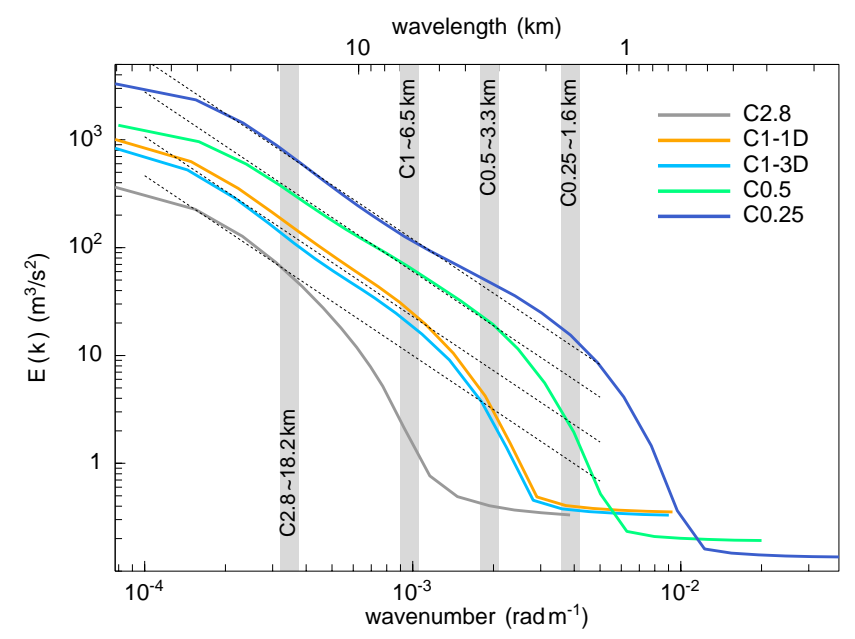

Figure 7. Kinetic energy density spectra computed from COSMO model output for 23 July 2013 averaged between 10:00 and 18:00 UTC at a height of $5 \mathrm{~km}$ a.g.l. The gray shaded areas represent wavelengths of 6-7 times the horizontal grid spacing of the different model runs. Dashed lines with $-5 / 3$ slope are plotted to aid identification of the inertial subrange.

differences in horizontal extent and precipitation amount are simulated: the $\mathrm{C} 2.8$ run has the smallest area covered by precipitation of all model runs and the maximum rain amounts $(15-20 \mathrm{~mm})$ are simulated in the high-resolution runs with 3D turbulence scheme (C1-3D, C0.5, C0.25). A common error of all model realizations is the lack of more widespread precipitation in the northwestern part when compared to radar observations (see Fig. 3a).

Due to the lack of observed and simulated precipitation, the 24 April case is not shown in Fig. 8. In the simulations for 25 April, a small west-east oriented area with precipitation is present somewhat north of and over the KITcube. Since only weak amounts of rain are simulated (less than $6 \mathrm{~mm}$ ) and the precipitation location is nearly identical in all model runs, this case also is not shown in Fig. 8. The radar-derived observations, however, do not show any precipitation in that area.

The spatial rain distribution on 26 April (Fig. 8, second row) reveals that the entire investigation area is covered by rain. In all model runs, there is a band with highest rain amounts from the southwestern corner to the middle of the eastern edge of the domain. The structure of this band is more or less the same in all model runs. Whereas the maxima (40-50 $\mathrm{mm}$ ) agree well with radar observations, the area with strong rain amounts is too small (see Fig. 3c). The radar observations also show a region without rain west of the KITcube and another area with maximum rain amounts of $30-40 \mathrm{~mm}$ in the north, both of these features are not captured by any of our model runs.

On 19 May, the simulations show widespread precipitation east and south of the KITcube (Fig. 8, third row). The overall spatial distribution again is rather similar in all model runs, except for one convective cell east of Cologne (marked by a black circle). Whereas C2.8 and C1-1D (both with 1D turbulence) simulate only moderate amounts of rain (6$8 \mathrm{~mm}$ ), all remaining runs simulate a small, but distinct, convective cell with precipitation accumulations of $30-40 \mathrm{~mm}$ (C1-3D) and even 40-50 mm (C0.5, C0.25). The higher grid spacing, together with the 3-D turbulence scheme, seems to create a more vigorous convective activity.

Several convective showers are simulated in the southern part of the investigation area (including the KITcube location) on 28 May (Fig. 8, fourth row). In that case, more differences in the spatial rain distribution between the individual model runs can be observed. For example, the convective cell marked by the black circle in the reference run $\mathrm{C} 2.8$ is not simulated by run C1-1D and only with reduced rain amount and shifted towards the south by the run C1-3D. With 500 and $250 \mathrm{~m}$ grid spacing, the cell is simulated again and the aggregation towards a convective line is visible. Another difference is the cloud-free region of the reference run east of the KITcube, which is also obvious from the radar observation (Fig. 3e). In all other model realizations, however, there are several convective showers ranging up to the latitude of Dortmund. Even if the amounts of rain differ somewhat, the convective cells to the west of the KITcube are simulated similarly in all model runs.

The summertime case of 23 July reveals the distinctive convective nature of the event due to the large number of convective cells in the southern part of the investigation area (Fig. 8, bottom row). Whereas both $1 \mathrm{~km}$ runs simulate more small-scale cells than run $\mathrm{C} 2.8$, the runs with higher resolution $(500$ and $250 \mathrm{~m}$ ) reveal cells of greater horizontal extent. Obviously, the convection is more organized at high resolution on that day. Northwest of the KITcube, radar measurements indicate a north-south oriented rain band with maximum amounts between 40 and $50 \mathrm{~mm}$ (Fig. 3f). This rain band, however, is not simulated by the reference run, as marked by the black circle. The $1 \mathrm{~km}$ runs already simulate a small region with convective rain in that area. The best agreement with radar observations is reached by runs with 500 and $250 \mathrm{~m}$ resolution. Furthermore, the latter runs also simulate convective rain north of the KITcube (marked by the red circle). Although both areas marked by circles do not correspond exactly to the radar-derived location of the cells, both sub-kilometer runs provide a significant improvement of the results when compared to the runs at lower resolution.

In summary, the spatial rain distribution for the days with moderate to strong synoptic forcing (i.e., 15, 25, 26 April, 19 May) is rather similar. On days with weaker synoptic forcing and weak mid-tropospheric winds (28 May, 23 July), differences in the location of convective precipitation, the size distribution, and organization of convective cells are simulated. Moreover, differences in the maximum rain amounts can be seen in all model runs. Hence, we now analyze the individual amounts of rain and some precipitation statistics. 


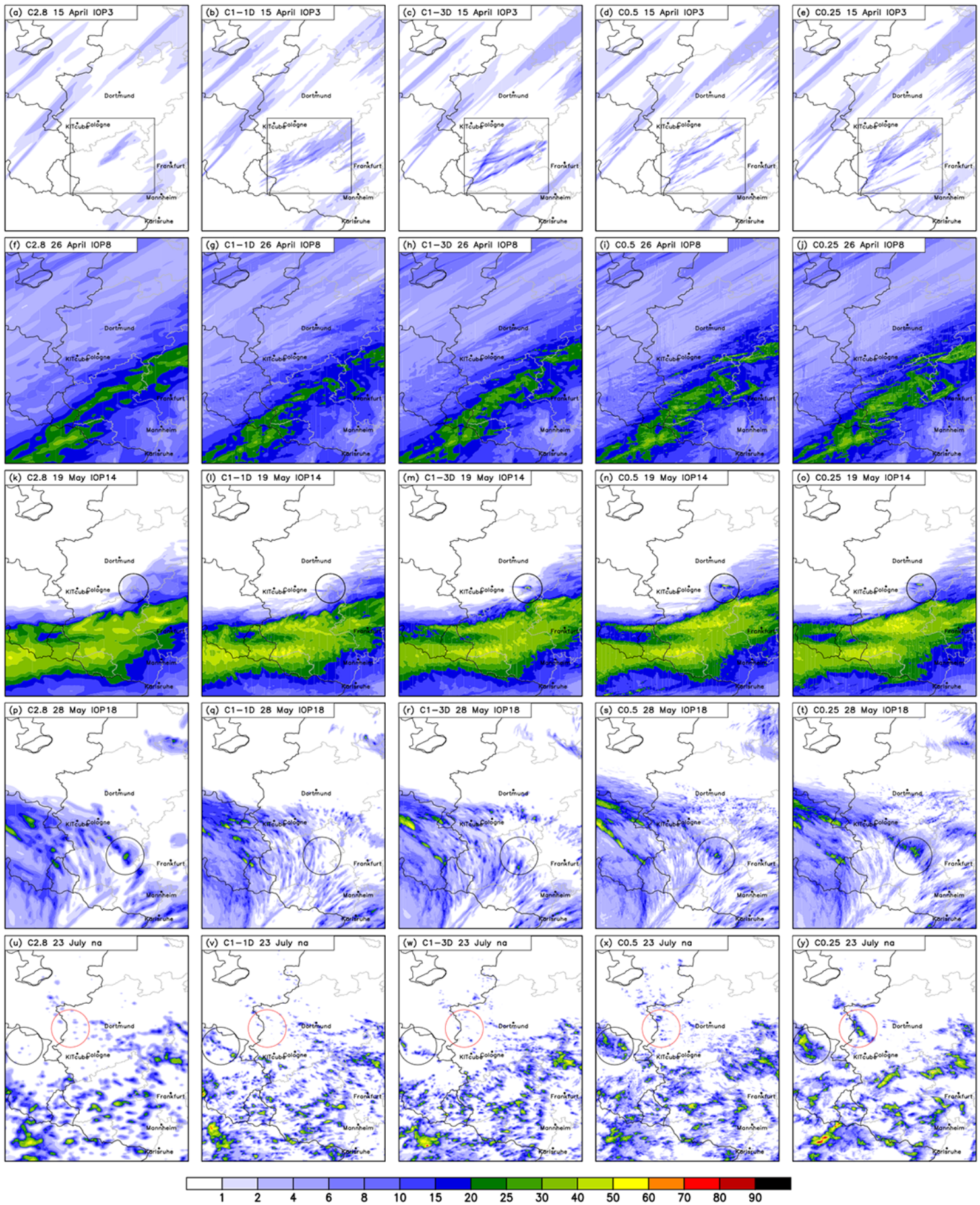

Figure 8. Simulated $24 \mathrm{~h}$ accumulated precipitation in $\mathrm{mm}$. Each row shows the results from 1 analyzed day for the different model runs. From top to bottom: 15, 26 April; 19, 28 May; 23 July 2013.

As 24 and 25 April show very small precipitation amounts only, these 2 days are excluded from the following analysis. For the remaining days, the simulated precipitation amount increases with model resolution (Fig. 9a), with the exception of 15 April, for which the C1-3D run simulates a slightly higher precipitation amount. However, the highest precipi- tation amount is always simulated by the runs with $250 \mathrm{~m}$ grid spacing. Although radar is not an instrument measuring precipitation in a quantitative sense (see, e.g., Rossa et al., 2005), the spatial coverage of radar-derived precipitation on the COSMO model grid of $2.8 \mathrm{~km}$ allows for a better comparison than point measurements with rain gauges. Whereas 
radar-derived precipitation is higher than the simulated one on 15, 26 April, and 23 July, the opposite is true for 19 and 28 May. It is worth noting that either all runs reveal lower or higher precipitation amounts than derived by the radar. When neglecting 24 and 25 April again, the largest deviations from the reference run are found for the summer case of 23 July with an increase of $48 \%$ by the $250 \mathrm{~m}$ run. On this day, this model run is also closest to the radar-derived precipitation amount, indicating an improved forecast quality for the $24 \mathrm{~h}$ domain-accumulated precipitation amount at least. Other days exhibit also large deviations from the reference run, e.g., 15 April (23-34\%). The percentage increase of the $24 \mathrm{~h}$ precipitation amount is lowest for 26 April and 19 May with maximum deviations from the reference run of 7 and $4 \%$, respectively. Those days also have the highest precipitation accumulations of all analyzed days.

A more detailed look at the precipitation statistics is provided by the box-and-whisker diagram in Fig. 9c. An important variable for hydrological processes and flash floods is the simulated maximum precipitation amount. Our results show that increasing the model resolution does not lead to systematically increased maximum precipitation amounts. However, with the exception of both $1 \mathrm{~km}$ runs for 26 April, the reference run with $2.8 \mathrm{~km}$ grid spacing always has the lowest maximum precipitation amount. Apart from that, large differences can occur, as can be seen, e.g., on 23 July, when the simulated maximum increases from 56 to $95 \mathrm{~mm}$ in $24 \mathrm{~h}$. The median of the $24 \mathrm{~h}$ precipitation amount exhibits only small variations without any systematic response to model resolution. Stronger variations can be seen for the 75 percentiles, particularly on 26 April. On that day, a comparatively small increase of domain-integrated precipitation is simulated with increased model resolution. As the 25 percentiles, the median, and the simulated maximum precipitation amount show little variation only, the increase of the 75 percentiles seems to be responsible for the higher precipitation amount. When neglecting the days with small amounts of precipitation (15, 24, 25 April), the comparison with radar-derived observations reveals that the median is rather well captured by the models on 19, 28 May, and on 23 July, whereas all model configurations have significantly lower median values on 26 April. The reference run on that day even exhibits a 75 percentile lower than the radar-derived median. This reflects the smaller precipitation amounts of the models when compared to the observations. There are also large differences concerning the maximum precipitation amount. While the difference on 26 April is comparably small, stronger deviations between observed and simulated maximum precipitation amounts are obvious on 19, 28 May, and 23 July.

\subsection{Temporal evolution of precipitation}

An important aspect of simulating precipitation is its temporal evolution, i.e., the onset, duration, and end of convective precipitation. Although the initiation of individual convective
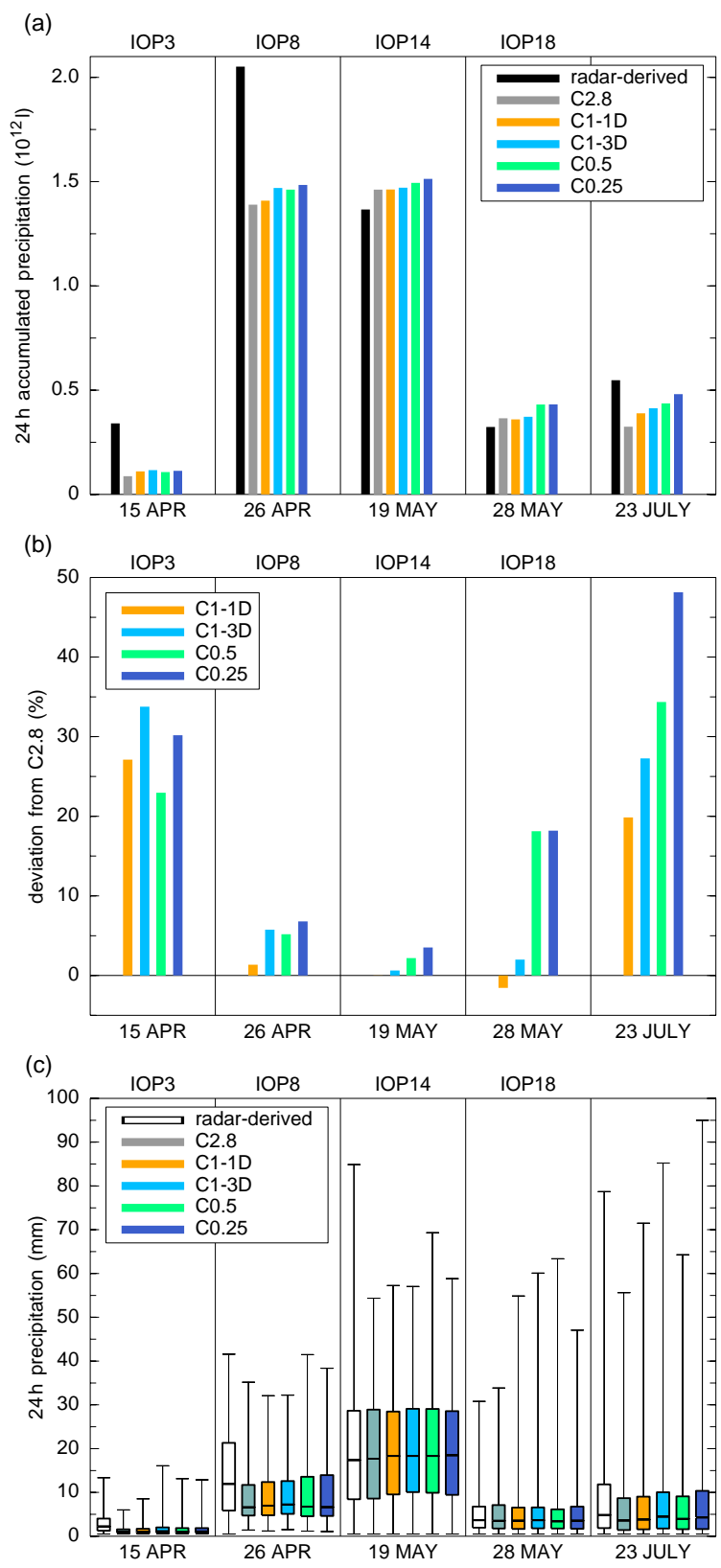

Figure 9. Domain-accumulated $24 \mathrm{~h}$ precipitation amount (a), deviation from reference run (b), and box-and-whisker diagram (c) exhibiting the median, the 25 and 75 percentiles, as well as the minimum and maximum precipitation amounts. Note that in (c) only grid points with precipitation larger than $0.5 \mathrm{~mm}$ are considered to prevent too small median values in case of small fractions of the area with convective precipitation.

cells may vary largely over a large domain in situations with air mass convection, our interest concentrates on the overall temporal evolution in our common investigation area. Therefore, we now analyze the temporal evolution of mean precipitation for the domain given in Fig. 8. 


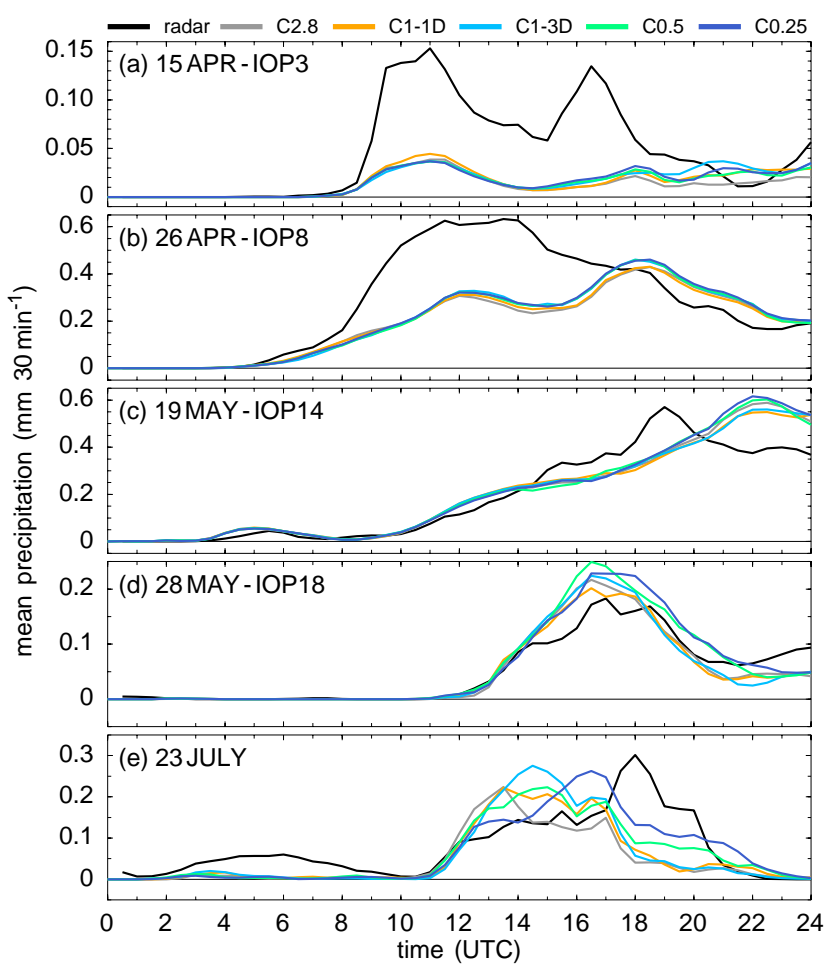

Figure 10. Simulated and radar-derived mean precipitation rates of the common investigation area.

As can be seen in Fig. 10, two dominating peaks of precipitation at 11:00 and 16:30 UTC are observed by the radar on 15 April. Towards the end of that day, the mean precipitation rate increases again. The onset of simulated precipitation in all model runs is only $30 \mathrm{~min}$ later than observed. Whereas the first dominating peak at 11:00 UTC is simulated at the same time, the second peak is simulated $1.5 \mathrm{~h}$ later. Furthermore, the simulated precipitation rates are considerably lower than the ones derived from radar measurements. All simulations show a similar mean precipitation rate until the time of the secondary precipitation peak. Later on, the C2.8 (C1-3D) run simulates the smallest (largest) precipitation rates of the individual model configurations.

On 26 April, both simulated and radar-derived mean precipitations start at the same time (04:00 UTC). After a strong increase, the observations show a broad maximum between 11:30 and 14:00 UTC. During that time, all simulations show precipitation rates that are half of the observations only. There is a gradual decrease in the observed precipitation rate to $0.2 \mathrm{~mm} 30 \mathrm{~min}^{-1}$. The simulations, however, reveal another increase in convective activity with a peak at 18:30 UTC. This peak is slightly higher than the observed precipitation. The decrease of convective rain in the evening is simulated with values similar to those observed. Although all curves from the simulations are located close together, the runs with the 1-D turbulence (C2.8 and C1-1D) scheme show slightly lower mean precipitation rates than the remaining model configurations.

After a first local maximum at 05:30 UTC, radar-derived precipitation on 19 May increases gradually up to its maximum at 19:00 UTC. The models capture the onset and intensity of the mean precipitation rather well but the maximum rain intensity is simulated $1.5 \mathrm{~h}$ later than observed. Again, all models have similar rain intensities, with the 1-D turbulence scheme having slightly lower values.

On 28 May, observed and simulated precipitations start again at the same time (11:30 UTC). The maxima are simulated at 16:30 UTC, which is only 30 min earlier than the observed peak. Later on, precipitation rates decrease but start to rise again after 21:00 UTC. Besides the higher maximum precipitation rates, the simulations show a rather good agreement with the observations on that day.

The air mass convection case of 23 July reveals some showers in the night and early morning (until 10:00 UTC). During that time, the models simulate only very little amounts of rain. After 11:00 UTC, simulated and observed precipitations increase simultaneously with similar values. Whereas the observations show a kind of plateau with more or less constant rain rates between 14:00 and 16:00 UTC, followed by a strong increase to its maximum at 18:00 UTC, the simulated rain rate maxima occur at different times between 13:30 and 16:30 UTC. Furthermore, all simulated peaks are somewhat lower than the one derived by radar. After their respective maximum, the mean rain intensities decrease again to almost $0 \mathrm{~mm} 30 \mathrm{~min}^{-1}$ at 23:30 UTC.

Disregarding the 2 days with no or comparably small precipitation amounts ( 24 and 25 April), the analysis of the temporal evolution of precipitation shows that the simulated onset and duration of rain corresponds well to the radar-derived measurements. Furthermore, there is no systematic over- or underestimation of the maximum rain intensity. For most of the days, the rain intensities of the models with a 1-D turbulence scheme (C2.8, C1-1D) are lower than those simulated with a higher model resolution using a 3-D turbulence scheme. This indicates that the higher grid spacing of the model allows for the development of stronger updrafts and more intense convective showers. With the exception of 15 April, all C1-3D runs with the 3-D turbulence scheme show higher rain intensities than the respective run with a 1-D scheme, where turbulence occurs only vertically (C1-1D). One possible explanation for this could be that the 3-D schemes somewhat increases the turbulent mixing in the PBL. Thus, small-scale gradients of temperature and moisture are reduced which locally can be important for the initiation or enhancement of deep convection. Another finding evident from Fig. 10 is the fact that the relative difference of simulated rain intensities is smallest on 26 April and 19 May. These days also had the highest $24 \mathrm{~h}$ precipitation amount (see Fig. 9a) and the strongest mid-tropospheric winds (see Fig. 2). We therefore hypothesize that the influence of higher 
grid spacing is stronger on days with weak synoptic-scale forcing and vice versa.

\subsection{Characteristics of cloud liquid water path}

To assess the influence of the model resolution on the simulated clouds, we now analyze the cloud liquid water path (LWP; here as the sum of cloud water and rain water) of all days and all configurations. Figure 11 illustrates the time evolution of domain-averaged LWP and the fraction of grid points with LWP values exceeding $1 \mathrm{~g} \mathrm{~m}^{-2}$. In general, the temporal evolution of the domain-averaged LWP has a similar shape as the rain intensities displayed in Fig. 10. As expected, the increase of the LWP always starts earlier than the respective rain increase. On days with predominantly convective showers (15 April, 28 May, and 23 July), the time delay is $1-2 \mathrm{~h}$, whereas there is also a slowly increasing LWP on days with stronger large-scale forcing (26 April, 19 May) on which the first rain is simulated $4-5 \mathrm{~h}$ later. This difference in the time delay suggests that under convective situations forced by local processes, the growth of the clouds is faster than in situations with strong large-scale forcing, where a more gradual growth of the clouds (i.e., a slower transition from shallow to deep convection) is typical. Non-precipitating clouds were simulated for the evening of 24 April. Only the C1-1D run simulates some clouds in the early morning, whereas the remaining runs do not. Further inspection of the cloud field revealed some isolated low clouds in that run, possibly due to a slightly colder PBL (not shown). The largest differences in mean LWP between the different model resolutions occur on 25 April, a day with only very small amounts of rain (less than $6 \mathrm{~mm}$ in $24 \mathrm{~h}$ ). On that day, the runs with a 1-D turbulence scheme (C2.8, C1-1D) show noticeable higher mean values than the runs with the 3-D turbulence scheme, whereas the temporal evolution is similar in all runs. Mean rain intensities, however, are rather similar with values between 0.05 and

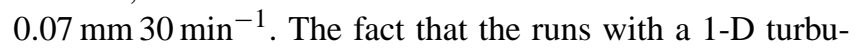
lence scheme simulates larger LWP values is also true for 15 April (09:00-12:00 UTC) and 26 April (morning and afternoon). As can be seen from the fraction of grid points exceeding $1 \mathrm{~g} \mathrm{~m}^{-2}$ in the right column of Fig. 11, these periods are characterized by a larger cloud cover. As the maximum LWPs are very similar or even lower (not shown), we therefore conclude that the larger mean LWP values are due to a larger fraction of grid points with simulated clouds than in the runs with a 3-D turbulence scheme. On the contrary, the area with simulated clouds is smaller in the runs with a 1-D turbulence scheme on 19 May for most of the day whereas the mean LWP is rather similar in all runs. This means that the lower rain amounts (despite similar rain intensities) in the runs C2.8 and C1-1D (see Fig. 9) can be attributed to somewhat fewer clouds in the area of investigation. A possible explanation for the higher LWP in the runs with 1-D turbulence scheme for the aforementioned periods might be a stronger entrainment of colder air from the free troposphere into the PBL. On 15 April at 10:00 UTC for example (not shown), the PBL is more than $1 \mathrm{~K}$ colder in the runs with a 1-D scheme. A shallow cloud layer between 800 and $1300 \mathrm{~m}$ a.g.l. is simulated in those runs, whereas there are no clouds in the runs with a 3-D turbulence scheme. Although there is not much variation in the $24 \mathrm{~h}$ precipitation amount, our results show that the choice of the turbulence scheme can have a strong influence on PBL clouds.

\subsection{Probability density functions and subgrid-scale variability of the reference run $\mathbf{C 2 . 8}$}

In low-resolution models, clouds are parameterized based on assumptions regarding the subgrid-scale variability of thermodynamic variables, with a prescribed probability density function (PDF) of fixed form and width being used (e.g., Tiedtke, 1989). The PDFs of cloud and convection-related variables, however, can vary significantly over space and time. To investigate the impact of higher grid spacing on cloud and precipitation development, we now analyze a number of convection-related variables with their PDFs. Doing this, the variability of these parameters can be studied and it is found how the variability changes with model resolution. Analysis of PDFs also allows for the determination of the most probable values, which provides more insights into the atmospheric phenomena than analyzing mean or median values. At first, we focus on PDFs calculated inside the common investigation area for the entire simulation period, meaning that every half-hourly model output over the entire simulation time of $24 \mathrm{~h}$ is taken into account (hereinafter referred to as $24 \mathrm{~h} \mathrm{PDF})$.

As was already pointed out in Sect. 3.1, several meteorological phenomena show a strong dependance on model resolution. We therefore also expect significant differences of the PDFs. At first, we analyze the distribution of the convergence of the $10 \mathrm{~m}$ wind, which shows larger values with higher grid spacing (see Fig. 5). As can be seen from Fig. 12a, the PDFs of the $10 \mathrm{~m}$ wind convergence on 23 July 2013 become wider with increasing model resolution. As a consequence, the probability of the dominant value (i.e., the maximum of the PDF) decreases. The dominant value of all runs always has a negative sign and its location shifts slightly to smaller values with increasing model resolution. Although the two model runs at $1 \mathrm{~km}$ grid spacing are largely similar, the 3-D scheme (C1-3D) produces marginally smaller values of convergence and the probability of the dominant values is higher than that of the 1-D scheme (C1-1D). The characteristics of this day also apply to the other days under investigation. The only difference is the fact that on days without any or with small amounts of rain only, the distributions are narrower than on days with strong precipitation. This is due to the stronger convergence induced by downdrafts and cold outflows of convective systems at their leading edge. The gen- 

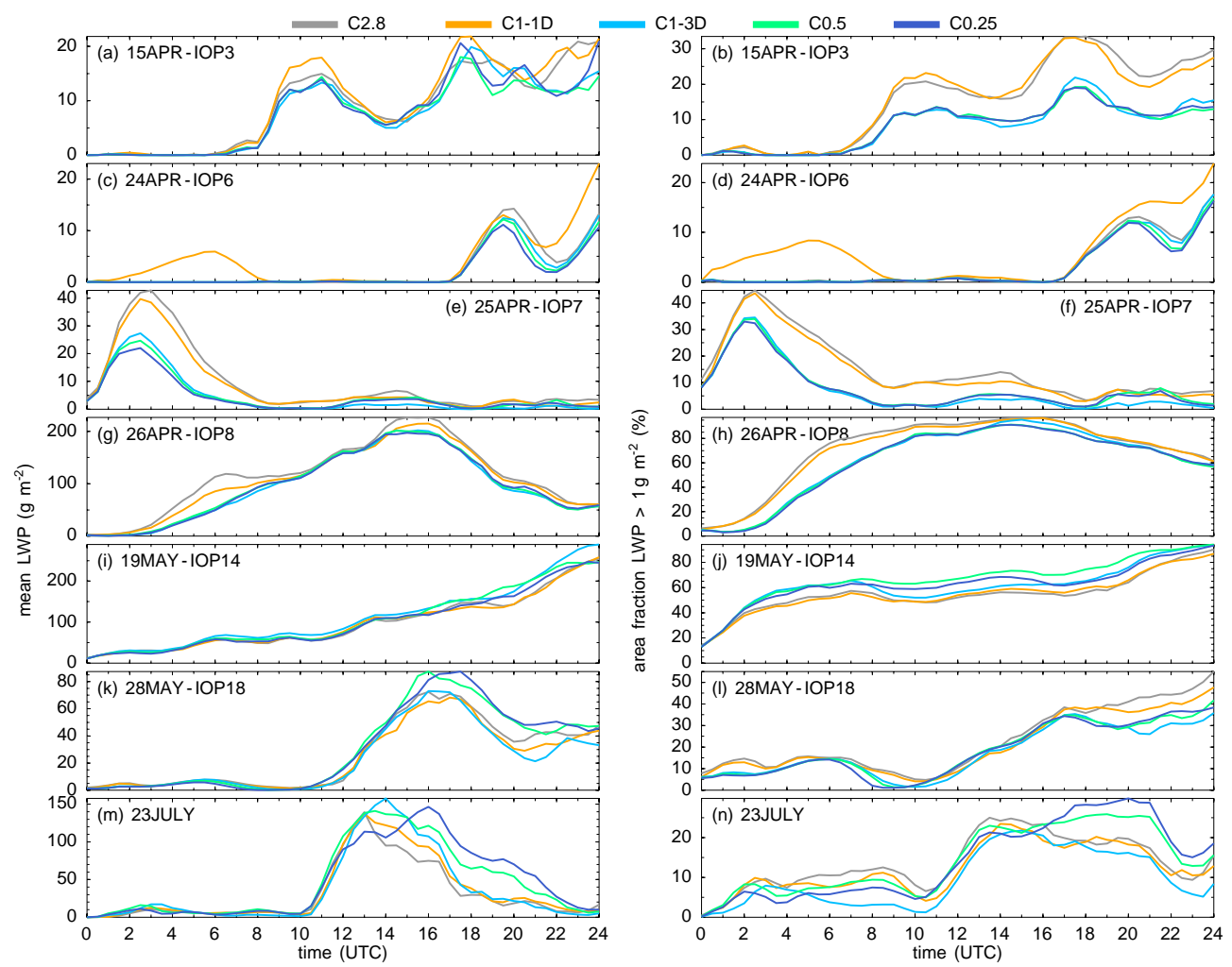

Figure 11. Domain-averaged liquid water path (left column) and fraction of grid points with liquid water path values exceeding $1 \mathrm{~g} \mathrm{~m}^{-2}$ (right column) in the common investigation area.

eral dependance on the model resolution, however, is present on all days.

For continuity reasons, the convergence of the low-level wind must lead to the lifting of air parcels. Figure $12 \mathrm{~b}$ shows the PDFs of vertical velocity in the PBL at a height of $~$ 400 ma.g.l. As expected, the response of the PDFs to model resolution is identical to that of the low-level wind convergence: there are stronger up- and downdrafts at higher resolutions with reduced probabilities of the dominant values. The analysis of PDFs of the vertical velocity at higher levels $(850,700$, and $500 \mathrm{hPa})$ indicates that the systematic behavior observed in the PBL is persistent at all heights. Although their probabilities of occurrence are very low, the tails of the distribution become larger when reducing grid spacings.

The PBL characteristics and their impacts on the triggering and/or dynamics of convection depend on the partitioning of the available energy (net radiation minus ground heat flux) into sensible and latent heat, which in turn is determined by soil moisture. As the land use and soil type are identical in all runs, since they have been interpolated to a higher resolution, only small differences in the $24 \mathrm{~h}$ PDFs of the net radiation are observed (not shown), which is due to varying cloudiness or rain. Whereas the distributions of the latent heat flux are similar for all model resolutions, there are minor differences for the PDFs of the sensible heat flux (not shown). The highresolution runs have a more pronounced peak with slightly narrower PDFs compared to the runs at low resolution. These differences, however, occur for negative values simulated for stable, nighttime conditions only and are probably related to the 3-D turbulence scheme. The PDFs of the positive fluxes (from the ground to the atmosphere) are very similar for all model resolutions.

As the $24 \mathrm{~h}$ PDFs of the energy balance components do not show any major differences, we now analyze the resolution dependance of the near-surface temperature and moisture with the days 25 April and 23 July being used as examples (Fig. 13). These days are chosen because they show the largest differences of the PDFs. The other days show either a similar behavior with less pronounced differences or only negligible differences between the PDFs. Furthermore, these days are characterized by (i) very little amounts of rain on 25 April and (ii) strong convective showers on 23 July. As the latent heat flux does not respond to model resolution and the large-scale advection of moisture is supposed to be more or less similar in all model runs, the PDFs of the $2 \mathrm{~m}$ specific humidity are rather similar in all runs of the respective day. Moreover, the dominant values are identical or very close to each other. Although the PDFs of the $2 \mathrm{~m}$ temperature generally have a similar shape, there are nevertheless small differences: (i) the runs C2.8 and C1-1D have their secondary maximum at somewhat lower temperatures than the remaining runs on 25 April and (ii) the same model configurations 

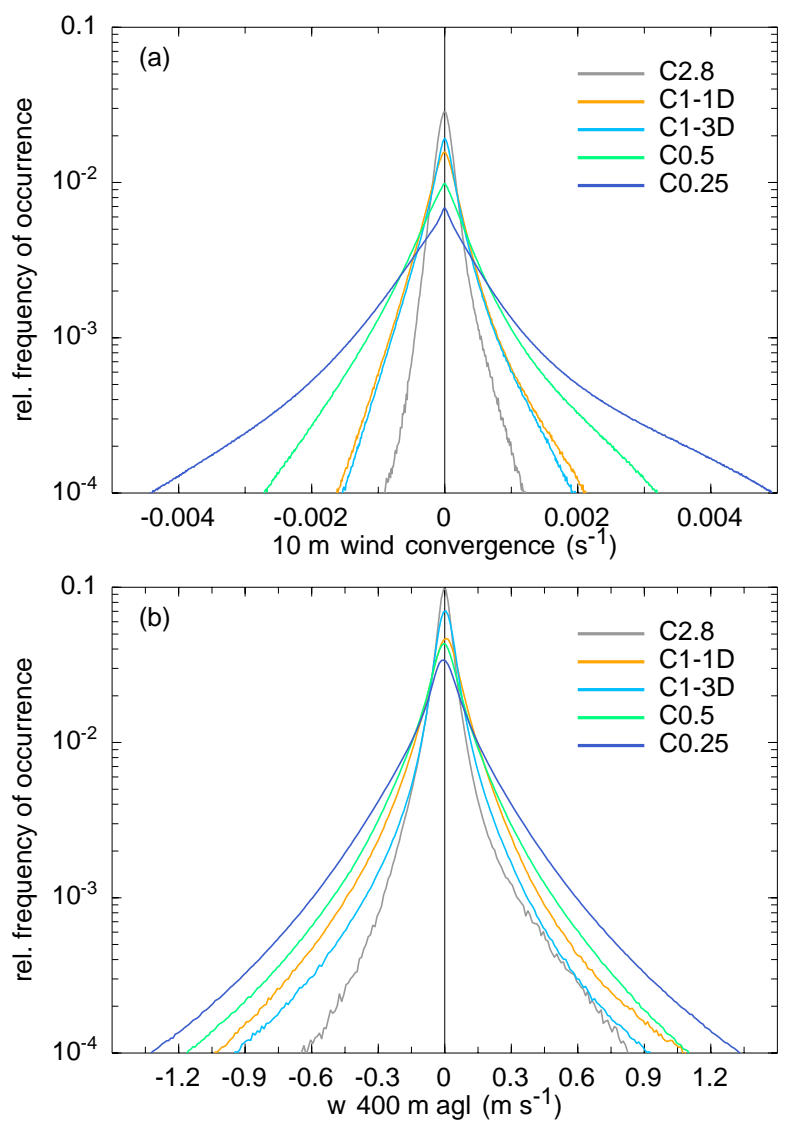

Figure 12. Probability density functions of the $10 \mathrm{~m}$ wind convergence (a) and vertical velocity at $\sim 400$ m a.g.l. (b) on 23 July 2013 .

do have their dominant value at slightly higher temperature on 23 July. The small differences in the PDFs of specific humidity and temperature can have strong impacts on the nearsurface relative humidity. As can be seen in Fig. 13 (right), there are marked discrepancies between the dominant values of the individual PDFs: on 25 April, the dominant value of the relative humidity is $53 \%$ for runs $\mathrm{C} 2.8$ and C1-1D, whereas for the remaining runs, it is $85 \%$. For 23 July, there is even a systematic shift to higher values with increased model resolution. This tendency towards higher dominant values of relative humidity also is a feature of the other days under investigation. This has important implications for the evolution of PBL-driven convection. As was already pointed out by several authors (e.g., Crook, 1996), small variations in boundary-layer temperature and moisture $\left(1^{\circ} \mathrm{C}\right.$ and $1 \mathrm{~g} \mathrm{~kg}^{-1}$, respectively) can make the difference between no initiation and intense convection. Since our results reveal strong differences in the dominant values of near-surface relative humidity, this also affects the height of the lifting condensation level or the level of free convection. Especially for the July case with scattered convection, the implications of the differences in the PDFs are reflected by the different precipitation structures (see Fig. 8). However, also on days with almost no simulated precipitation (25 April, Fig. 13), the dominant values of near-surface relative humidity can show strong variations with model grid spacing. This indicates that the PDFs are modified not only by the different rain amounts and locations as observed for the summertime case of 23 July but also by the pure response to model resolution without feedbacks from moist convection.

\subsection{Temporal analysis of dominant values and variances}

The previous section revealed the strong response of selected convection-related variables to model grid spacing based on PDFs for the entire $24 \mathrm{~h}$ simulation period. However, it is also of interest to analyze the temporal development of their characteristics. As the analysis of all parameters describing the distribution of variables, such as the variance, the mean, the median, the dominant, and extreme values, would require too large an expenditure, we focus our analysis in this section on the dominant values and the variances of the distributions. Figure 14 presents these characteristics for the $2 \mathrm{~m}$ temperature and $2 \mathrm{~m}$ specific humidity in steps of $30 \mathrm{~min}$ for the entire simulation domain of all days under investigation. The common color scale for all days somewhat limits the visibility of the variability of model runs for the individual days. Therefore, the deviations of these values from those of the reference run are also displayed in the right column. The temporal evolution of the dominant $2 \mathrm{~m}$ temperature shows a daily cycle linked to the warming of the near-surface air, with larger values around noon and in the afternoon. Maxima of up to $33^{\circ} \mathrm{C}$ are reached for the summertime case of 23 July. A significant drop of the dominant values from 17 to $8^{\circ} \mathrm{C}$ occurs on 26 April between 13:30 and 14:00 UTC for all model simulations of this day. The analysis of the individual PDFs of these times shows a bimodal distribution with local maxima at the above values. Although the overall shape of the PDF is similar, the dominant value shifts between these two values at 14:00 UTC. Inspection of the deviation from the dominant values of the reference run with $2.8 \mathrm{~km}$ grid spacing reveals strong differences of more than $5 \mathrm{~K}$ for the different model realizations at the same time. The reason for the bimodal distribution is the convective precipitation falling only in parts of the simulation domain: the PDFs of the $2 \mathrm{~m}$ temperature in the morning hours exhibit one prominent peak (not shown). In the course of the day, convective rain intensifies while progressing eastwards (see temporal evolution in Fig. 10). This leads to relatively warm temperatures in the eastern part of the simulation domain, while the rain falling in the western parts leads to cooling. Consequently, a bimodal temperature distribution evolves with the change of the dominant value occurring at 14:00 UTC.

There are also periods in which the dominant values change with model resolution for a given time. On 19 May between 12:00 and 16:00 UTC, for example, the runs with the 1-D turbulence scheme show a dominant value at the 

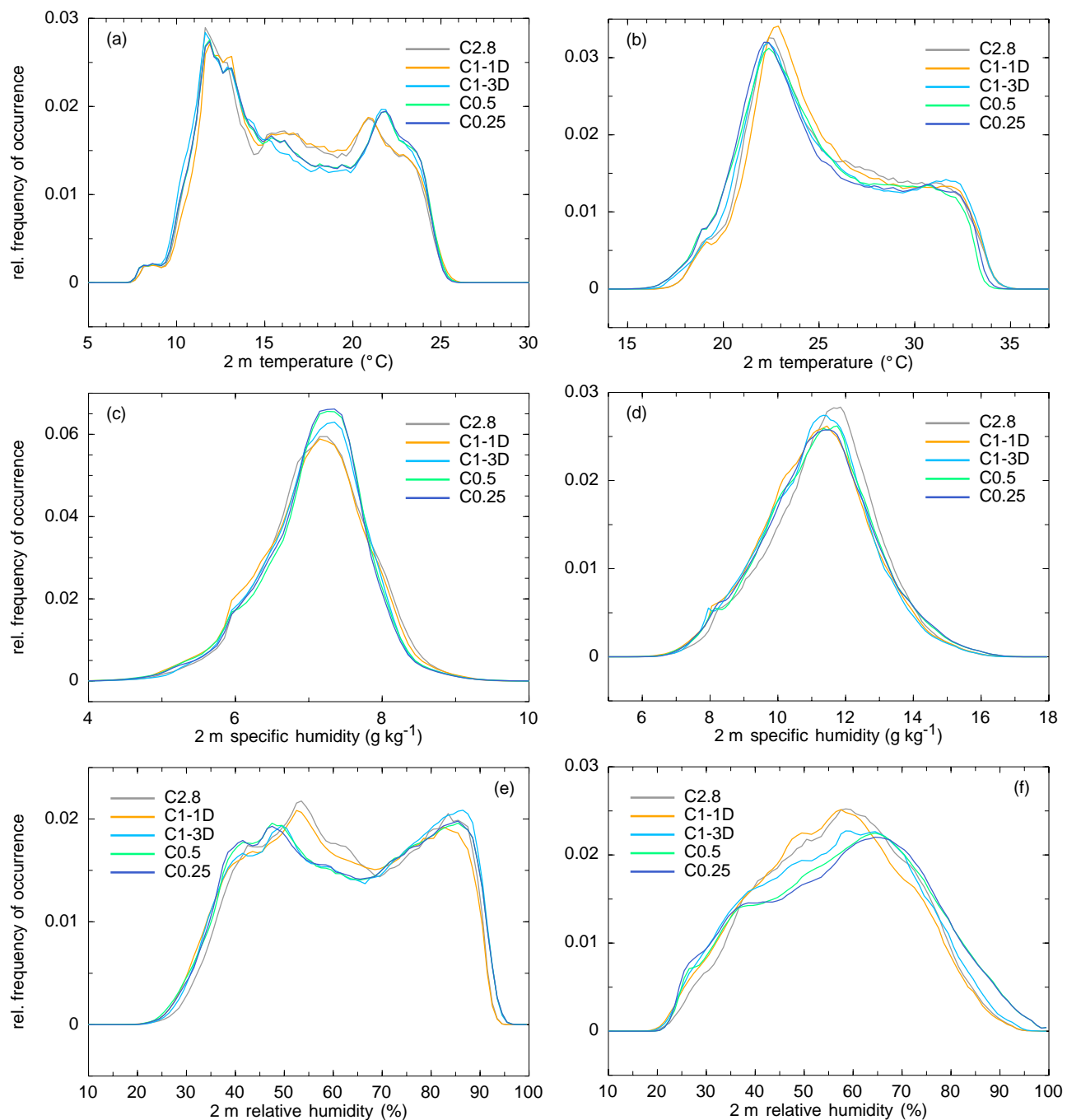

Figure 13. Probability density functions of the $2 \mathrm{~m}$ temperature (a, b), $2 \mathrm{~m}$ specific humidity (c, d), and $2 \mathrm{~m}$ relative humidity (e, f) on 25 April (left) and 23 July 2013 (right).

warmer peak, whereas the remaining runs have their maxima at the colder one. As the model orography does only change from 2.8 to $1 \mathrm{~km}$, these differences can be attributed to different meteorological processes (slope winds, convergence, PBL processes in general) resulting from different model resolutions only. The same holds for the negative deviation of the high-resolution runs on 23 July around 18:00 UTC.

Concerning the variance of the $2 \mathrm{~m}$ temperature, we find the highest values on days with the largest integrated rain amount (26 April, 19 May, 23 July). The individual maxima coincide with phases of larger dominant values. An important finding is the fact that the variance for a specific day does not necessarily increases with model resolution. Whereas a tendency of increased variance can be seen for most of the analyzed cases and times, there are three longer time periods on 25, 26 April, and on 19 May, where the $2 \mathrm{~m}$ temperature variance decreases with model resolution. Differences in pre- cipitation intensity or amount cannot be responsible for this behavior, since the total rain amounts and timings of precipitation for these phases are very similar in all model runs. We therefore suspect that besides the different horizontal and vertical grid spacings, the use of the 3-D turbulence scheme might play a role. Between 14:00 and 18:00 UTC on 23 July, the increase of the variance with resolution most probably is related to the later rain maximum simulated at high resolutions (see Fig. 10).

The dominant values of the $2 \mathrm{~m}$ specific humidity cover rather dry conditions with values of $5-6 \mathrm{~g} \mathrm{~kg}^{-1}$ on 26 April and moist conditions with values of around $12 \mathrm{~g} \mathrm{~kg}^{-1}$ on 23 July. There is no clear diurnal cycle as for the $2 \mathrm{~m}$ temperature, higher values are present during and after precipitation. As for temperature, there is a strong shift in the dominant values of $2 \mathrm{~m}$ specific humidity on 26 April around 11:00 UTC. This can also be attributed to the presence of a bimodal PDF, 

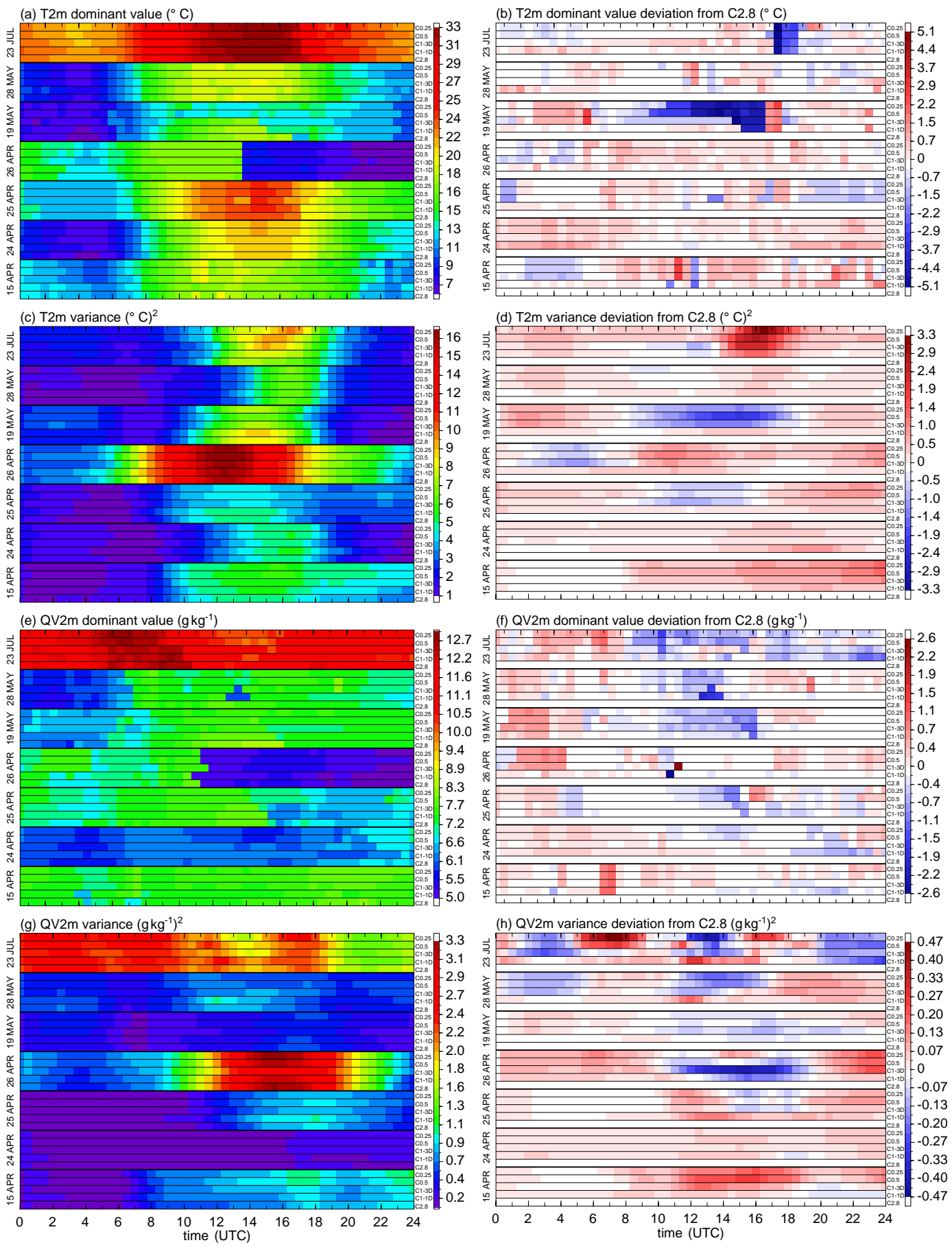

Figure 14. Dominant value (a, e) and variance $(\mathbf{c}, \mathbf{g})$ as well as their deviations from the reference run (b, d, f, h) of the PDFs of $2 \mathrm{~m}$ temperature (T2 m) and specific humidity $(\mathrm{QV} 2 \mathrm{~m})$ as a function of time for all cases analyzed. Each row represents the values of one model realization for the entire $24 \mathrm{~h}$ period in steps of $30 \mathrm{~min}$.

whose local maxima are clearly separated. The transition of the extreme value takes place between the two local maxima. Inspection of the deviation from the dominant value in the individual model runs of a specific day reveals no systematic response to model resolution. A higher grid resolu- tion leads to lower, larger, or almost unchanged dominant values. However, there seems to be a shift to lower dominant values with increased model resolution during phases with precipitation (e.g., 19 May 10:00-16:00 UTC, 23 July 09:00-24:00 UTC). Equally important, the $2 \mathrm{~m}$ specific hu- 
midity variance also reveals a strong, but not systematic, relationship to model resolution. The variance can increase up to $0.47\left(\mathrm{~g} \mathrm{~kg}^{-1}\right)^{2}$. On 15 and 24 April, the variances for almost the entire day are lower in the reference run than in all other runs at higher resolution. This is also true for the variance of the $2 \mathrm{~m}$ temperature. Both days are characterized by no or very low amounts of rain. Some of them correlate with the simulated precipitation (26 April: 11:00-19:00 UTC), but not all of them. On 23 July, the variance either decreases (02:0004:00 UTC) or increases (12:00-14:00 UTC) with resolution.

The final variable to be analyzed in this section is the vertical velocity which was already shown to have a strong response to model resolution (see Fig. 12). A widening of the PDF of the vertical velocity, accompanied by a decreasing probability of occurrence of the dominant value, is observed in the PBL as a result of stronger low-level wind convergence. To investigate the height dependency of the response to model resolution, we now analyze the vertical wind in the PBL (400 ma.g.1.), at 700 and at $500 \mathrm{hPa}$. As was already shown for the summertime case of 23 July, the variation of the location of the dominant value is rather low, changing between small positive and small negative values. However, these PDFs were calculated based on all data of the $24 \mathrm{~h}$ simulation period. The analysis of the dominant values of individual $30 \mathrm{~min}$ blocks reveals variations of $\pm 5 \mathrm{~cm} \mathrm{~s}^{-1}$ in the PBL and at $500 \mathrm{hPa}$ and somewhat slower values at the $700 \mathrm{hPa}$ level (not shown). The positive values occur primarily in phases of strong convective activity. The temporal variation is higher on days with moderate to large amounts of rain (26 April, 19, 28 May, 23 July) and lower on days with less or no precipitation (15, 24, 25 April).

The width of the PDF (described by the respective variance or standard deviation) is shown in Fig. 15. We see that the highest standard deviation occurs for the summertime case of 23 July (at all heights), whereas the smallest ones are simulated on days with less or no precipitation at all (24 and 25 April). When analyzing the response to model resolution for the individual days, two main features can be observed: (i) the standard deviation increases with higher grid resolution and (ii) the time period in which the standard deviation is higher also increases with grid resolution. The increase can be attributed to the widening of the PDFs with stronger upand downdrafts. As expected, the maximum standard deviation occurs during times of strong convective activity (e.g., 13:00-18:00 UTC on 23 July, 14:00-20:00 UTC on 28 May), which is also characterized by convective precipitation (see Fig. 10). An important finding is the fact that grid spacing effects are present not only in the PBL close to the terrain but also at greater heights.

\subsection{Grid spacing effects on convection initiation}

As was documented earlier, the PDFs of several meteorological variables may exhibit significant differences in shape and dominant value. However, the initiation of individual con- (a) w500hPa standard deviation

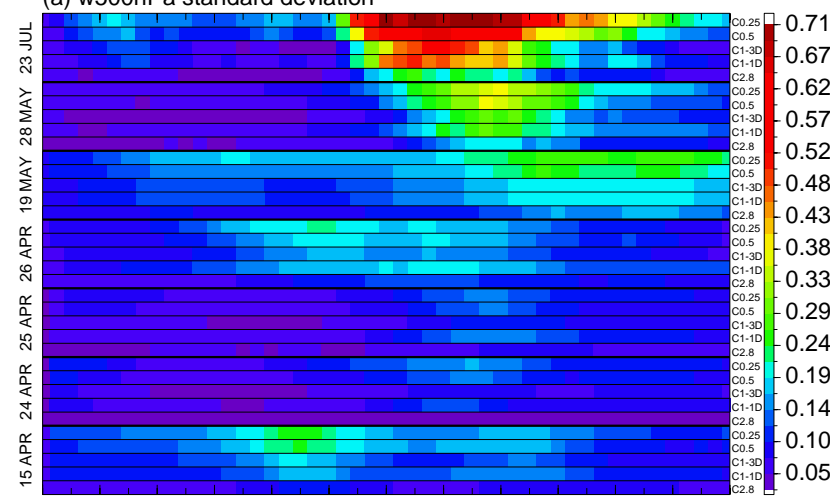

(b) w700hPa standard deviation

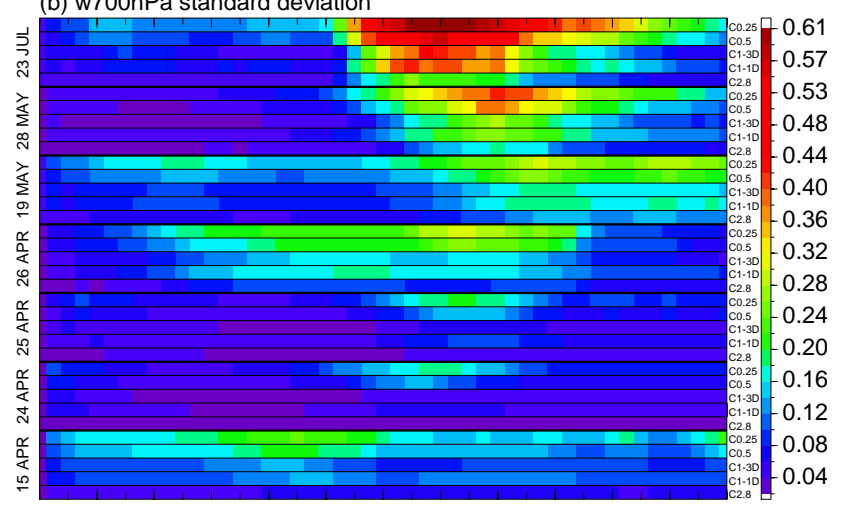

(c) w400m standard deviation

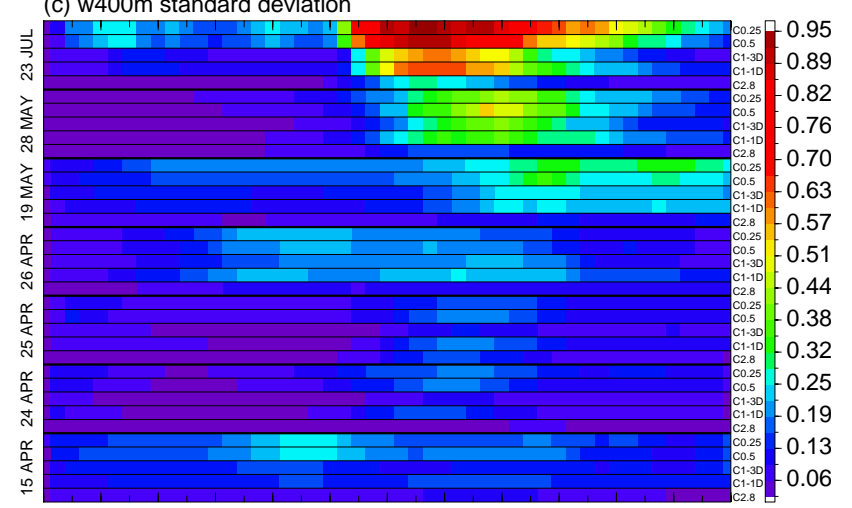

Figure 15. Standard deviation of the vertical velocity (in $\mathrm{m} \mathrm{s}^{-1}$ ) at $500 \mathrm{hPa}$ (a), $700 \mathrm{hPa}$ (b), and $400 \mathrm{~m}$ a.g.l. (c).

vective cells cannot be investigated by means of PDFs. We therefore now analyze the mechanisms triggering deep convection using mean values averaged over a specific region. Due to major differences in the simulations of the 23 July case, we focus on this day and the convective cell north of the KITcube marked by the red circle in the bottom row of Fig. 8. Only the run with $250 \mathrm{~m}$ grid spacing was able to reproduce the convection closely to radar observations (although the simulated convection is somewhat east of the observed one). Here, we analyze a number of convection-related parameters averaged over a rectangular domain around the convective cell. The runs with a horizontal grid spacing of 2.8 
and $1 \mathrm{~km}$ simulate only small amounts of rain between 12:00 and 21:00 UTC in the region of interest (Fig. 16). Whereas the $500 \mathrm{~m}$ run yields a short-lasting peak in the precipitation rate of $10^{-9} \mathrm{~L} 30 \mathrm{~min}^{-1}$ around 16:30 UTC, the $250 \mathrm{~m}$ run simulates stronger rain intensities between 16:30 and 20:30 UTC. The pre-convective conditions between 15:30 and 16:00 UTC show the lowest values of convective available potential energy (CAPE) in the $250 \mathrm{~m}$ run, but the differences between the individual model runs are rather small. Anyway, the stronger rain intensities cannot be attributed to a higher CAPE, but rather to the higher potential for convection initiation as a result of the lowest values of convective inhibition (CIN) of the $250 \mathrm{~m}$ run during that time. The higher CIN values of the other runs are a result of the weak precipitation leading to lower near-surface temperatures. There is a clear impact of model resolution on nearsurface convergence: whereas during nighttime conditions, the mean convergence is more or less similar, strong differences develop after 08:00 UTC as a response to diurnal heating and thermally driven secondary circulations. The higher the grid resolution is, the higher is the wind convergence. The runs with a grid spacing lower than or equal to $500 \mathrm{~m}$ show a gradual increase and decrease during daytime, whereas the $250 \mathrm{~m}$ run shows a secondary maximum between 18:00 and 19:00 UTC, which is related to the simulated convective cell and convergence associated with the cold air outflow. The lifting induced by convergence is also reflected by our simulations, where the domain-averaged upward vertical velocity at $500 \mathrm{~m}$ a.g.1. shows the same diurnal characteristics. As expected, stronger convergence in the higher-resolved runs also leads to stronger lifting. In order to assess the potential of low-level lifting for convection initiation, the vertical velocity needs to be higher than $w_{\mathrm{CIN}}=\sqrt{2 \cdot \mathrm{CIN}}$ (Trier, 2003) to overcome convective inhibition. Here, we calculate the velocity difference $w_{\text {diff }}$ as the difference between the maximum vertical wind below the level of free convection $w_{\max }$ and $w_{\mathrm{CIN}}$ :

$w_{\text {diff }}=w_{\max }-w_{\mathrm{CIN}}$.

If $w_{\text {diff }}$ is positive, there are sufficiently strong vertical winds to overcome CIN and CAPE can be released. Moreover, convergence also reduces the entrainment (e.g., GarciaCarreras et al., 2011) and equivalent potential temperature is higher in the convergence zones, which reduces the CIN. In Fig. 16a, the fraction of grid points with positive values of $w_{\text {diff }}$ is displayed. The reference run simulates no grid points fulfilling this criterion. With increasing grid resolution, the fraction rises as well, indicating a stronger potential of convection initiation. The fact that convection is not initiated around 14:30 UTC, when the fraction of grid points is highest, can probably be attributed to either not enough CAPE at the respective grid points or to the entrainment of drier environmental air in the middle troposphere, which may prevent cloud development. In the time immediately prior

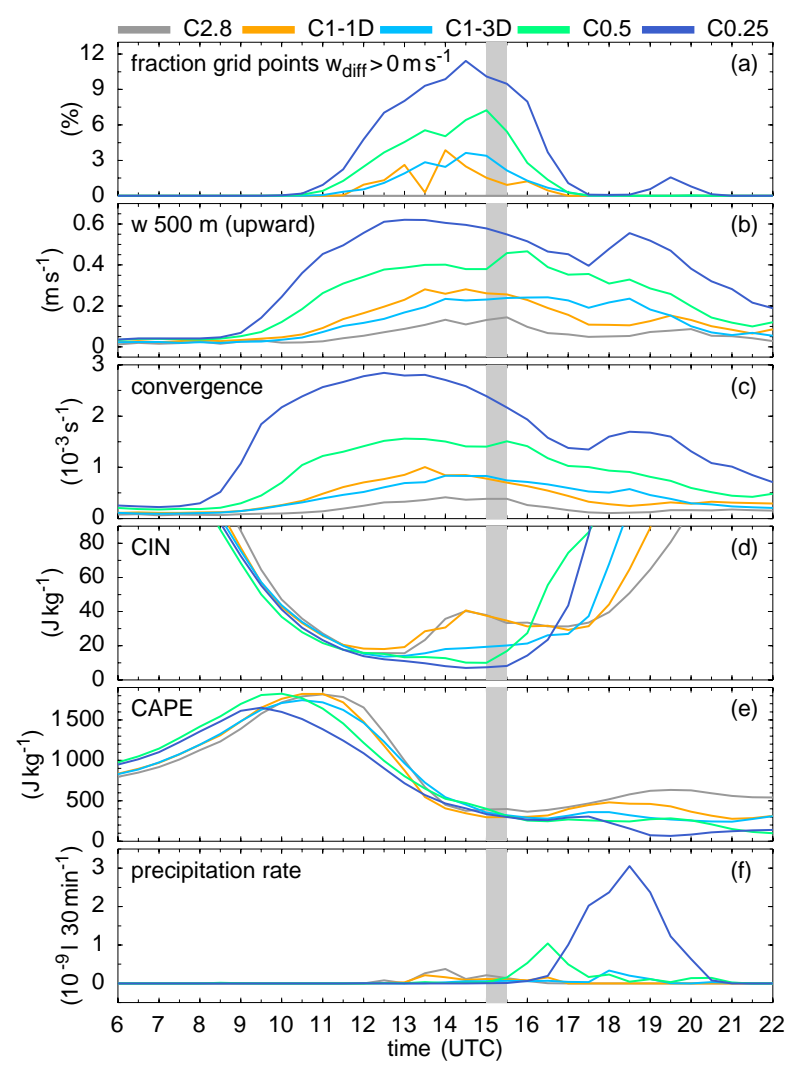

Figure 16. Domain-averaged fraction of grid points with positive $w_{\text {diff }}$ (a), vertical wind at 500 ma.g.l. (b) (only upward components), $10 \mathrm{~m}$ wind convergence (c), convective inhibition (d), convective available potential energy (e), and precipitation rate (f) on 23 July 2013. The gray shaded areas indicate the time of convection initiation of the $\mathrm{C} 0.25$ run.

to convection initiation (15:00-15:30 UTC, marked by the gray-shaded area in Fig. 16), there still is a superposition of convection-favoring processes: (i) strong convergence, lifting, relatively high fraction of grid points with positive $w_{\text {diff }}$, and (ii) minimum CIN with sufficient amounts of CAPE.

To link these convection-related parameters also to the existence and temporal evolution of clouds, domain-averaged profiles of cloud condensate (i.e., the sum of liquid water, ice, snow, graupel, and rain) are given in Fig. 17. It can be seen that the runs with coarser resolution than $250 \mathrm{~m}$ only simulate clouds with shorter lifetimes and distinctly less cloud condensate in the area of interest (left column in Fig. 17). The $500 \mathrm{~m}$ run has its maximum condensate at 16:00 UTC, which is $30 \mathrm{~min}$ prior to the rain maximum (see Fig. 16). However, only the $250 \mathrm{~m}$ run is capable of simulating deep convection, which is obvious from the domain-averaged cloud condensate values of $40 \mathrm{mg} \mathrm{kg}^{-1}$ stretching from the ground up to a height of over $11 \mathrm{~km}$. The highest cloud condensate values (nearly $400 \mathrm{mg} \mathrm{kg}^{-1}$ ) are simulated in a height of $5.5 \mathrm{~km}$ at the same time than the respective rain maximum (18:30 UTC). 

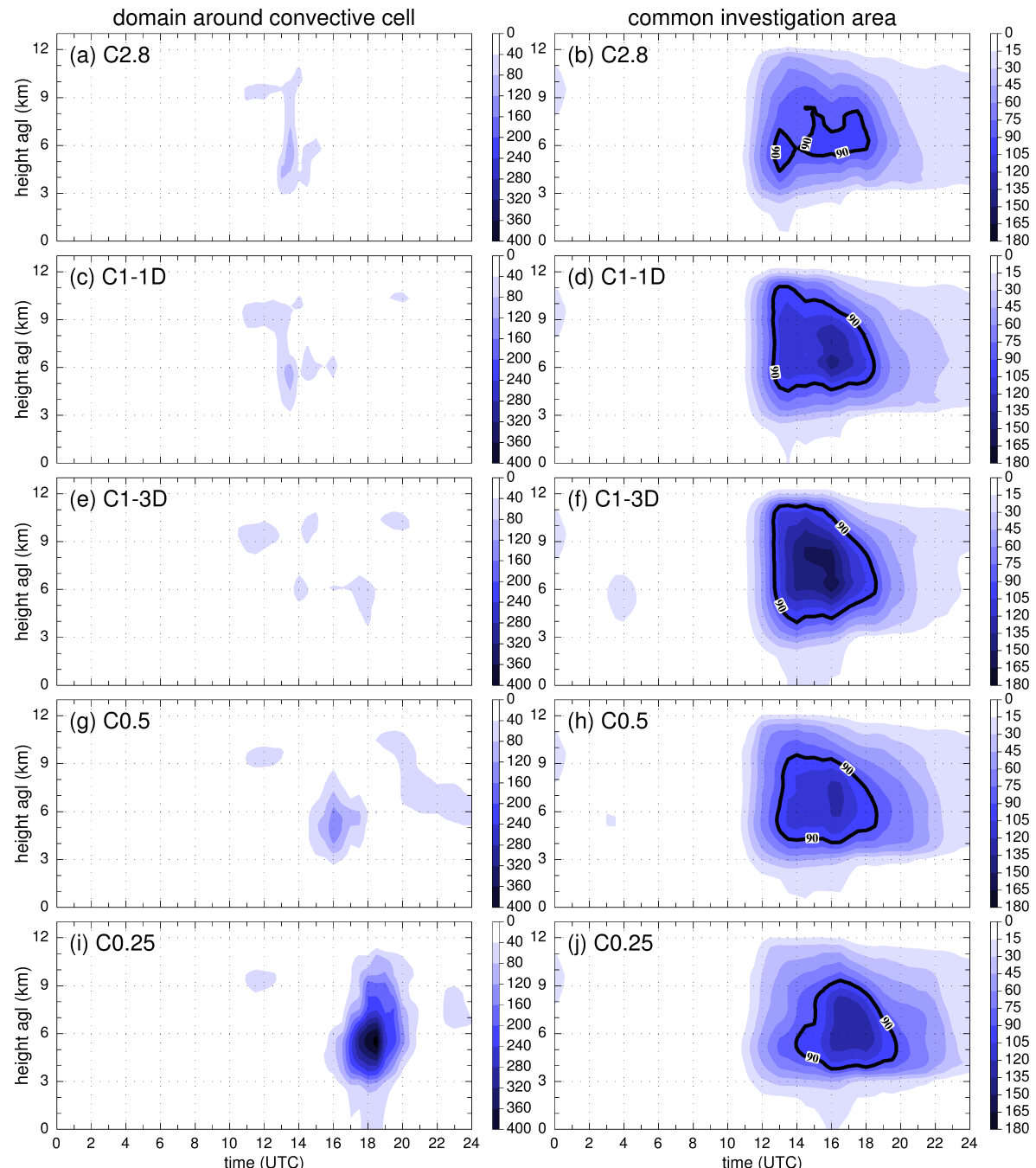

Figure 17. Domain-averaged vertical profiles of cloud condensate (liquid water, ice, snow, graupel, and rain) in $\mathrm{mg} \mathrm{kg}^{-1} \mathrm{on} 23 \mathrm{July} 2013$ for an area around the convective cell (left column) and the common investigation area (right column).

We like to extend the analysis of cloud condensate also to the entire common investigation domain (right column in Fig. 17). The formation of the main convective clouds starts more or less at the same time in all model configurations. Typical for such summertime conditions is the rapid growth of the clouds with short transition times from shallow to deep convection. All runs have a similar vertical extent and reach the tropopause at around $12 \mathrm{~km}$. Differences due to the grid refinement can be seen when analyzing the $90 \mathrm{mg} \mathrm{kg}^{-1}$ isoline: the reference run $(\mathrm{C} 2.8)$ only shows a small region of the atmosphere $(5-8 \mathrm{~km})$ where those values are reached. Surprisingly, the maximum height of this contour level is not reached by the $250 \mathrm{~m}$ run, but by both $1 \mathrm{~km}$ runs $(11 \mathrm{~km})$. The cloud condensate in the $\mathrm{C} 1-3 \mathrm{D}$ run is the highest of all model runs, in particular between 14:00 and 16:00 UTC. However, this run provides not the largest rain accumulations through- out the day as for most of the time, the runs $\mathrm{C} 0.5$ and $\mathrm{C} 0.25$ do have higher rain intensities.

\section{Conclusions}

The objective of this research was to investigate the variability of several convection-related parameters and how this variability changes with model resolution. Through a series of grid-refinement resolution tests, the applicability of the COSMO model in the gray zone and its large-eddy simulation capability were tested with horizontal grid spacings from $2.8 \mathrm{~km}$ down to $250 \mathrm{~m}$ for seven real cases over Germany. Six of the cases covered intensive observation periods of the HOPE field campaign conducted in spring 2013. Additionally, one summertime case of the same year with air mass convection was investigated. Although the general strategy of the $\mathrm{HD}(\mathrm{CP})^{2}$ project was to jump over the gray zone with 
the development and use of the ICON model for LES studies, operational models at forecast centers around the world still work in the gray zone. Hence, the performance of the COSMO model at these resolutions is of general relevance to the research community as well as to operational forecasters. Kinetic energy spectra derived from model output showed the expected $-5 / 3$ slope, as well as a dependency on model resolution with the effective resolution lying between 6 and 7 times the nominal resolution.

We found that increased resolution improves the ability of COSMO to capture gravity waves, to resolve thermals in the PBL, and to better account for triggering effects of low-level convergence zones. As the same orographic data set is used (just interpolated to the respective model resolution), these effects are solely a result of increased model resolution and not of a higher surface variability. Besides the horizontal grid spacing, the number of vertical levels was also increased. As the number of levels in the lowest $1000 \mathrm{~m}$ increases from 12 (at $2.8 \mathrm{~km}$ ) to 18 (at 500 and $250 \mathrm{~m}$ ), the representation of boundary-layer processes as well as the location and strength of the capping inversion are supposed to be better represented. The comparison of the simulated PBL profiles to observations is part of ongoing work. The next step would be to also use a higher-resolved orographic data set, but this is planned for future work. For the case of 28 May, however, simulations with $500 \mathrm{~m}$ grid spacing and a new topographic data set were performed. Results show very similar amounts of rain and also the location of precipitation is more or less identical.

For the six cases of the HOPE campaign, the location of precipitation was similar in all model configurations. However, the intensity of some convective cells was found to be dependant on grid resolution, leading to a higher $24 \mathrm{~h}$ rain amount at high resolutions. The summertime case, however, also showed strong differences with respect to the location as well as the intensity of convective rain. The timing of convective rain did not depend on model resolution, at least when averaged over the common investigation area. The percentage increase of total precipitation was largest for this case as well (neglecting the days with only very small amounts of rain). We therefore conclude that the synoptic forcing plays a larger role for the HOPE cases as for the summertime case, where no synoptic-scale upward forcing is present and that this larger role somehow limits the possible effects of a higher grid resolution. Similar to findings of Talbot et al. (2012), the data needed to force the individual domains and to initialize surface parameters have the strongest influence on the results.

At $1 \mathrm{~km}$ grid spacing, the simulations with 1-D and 3$\mathrm{D}$ turbulence provided rather similar results concerning rain amount and timing. However, the liquid water path and cloud condensate profiles revealed subtle differences between the two schemes for some days, but the 3-D scheme did not generate mesoscale features that appear more realistic than the 1-D model. Due to the lower computational costs, we recom- mend the 1-D closure at $1 \mathrm{~km}$ resolution for applications with a focus on convective precipitation.

The analysis of PDFs of several convection-related parameters showed strong deviations from the reference run when increasing resolutions. On the one hand, a widening of the PDFs was found for low-level convergence and vertical velocities (which increased their standard deviations); on the other hand, different dominant values were observed. The large jumps in the dominant values were attributed to the existence of bimodal distributions. In spite of these large differences in the PDFs, the sensitivity of rain especially in the synoptic-driven spring cases was rather low. This indicates that convection is not entirely controlled by PBL processes and also reflects the chaotic nature of convection in general. The results of our analyses show that the grid refinement did not lead to a convergence, suggesting that even higher resolutions might be needed for that. Numerical simulations with a grid spacing of $100 \mathrm{~m}$ will be subject of future work, which also will involve further investigations of the cloud size distribution and the distributions of cloud and precipitation particles. Additionally, the higher model resolution facilitates comparison with measurements from the HOPE field campaign. Moreover, these COSMO model runs can be compared with LES results obtained with the ICON model. Thus, potential differences in the realization of cloud-related processes between these two model systems can be identified.

Acknowledgements. The authors wish to thank the Deutscher Wetterdienst (DWD) for providing the COSMO model code, initial and boundary data as well as radar data. We thank the Federal Ministry of Education and Research (BMBF) for funding $\mathrm{HD}(\mathrm{CP})^{2}$ and the HOPE field campaign, as well as the involved teams for conducting the measurements. We are also grateful to I. Bischoff-Gauss (Steinbuch Centre for Computing SCC, KIT) for her help in running the COSMO model at very high resolutions on the HPC systems of SCC.

The article processing charges for this open-access publication were covered by a Research Centre of the Helmholtz Association.

Edited by: H. Russchenberg

\section{References}

Baldauf, M., Seifert, A., Förstner, J., Majewski, D., and Raschendorfer, M.: Operational convective-scale numerical weather prediction with the COSMO model: description and sensitivities, Mon. Weather Rev., 139, 3887-3905, doi:10.1175/MWR-D-1005013.1, 2011.

Barthlott, C., Corsmeier, U., Meißner, C., Braun, F., and Kottmeier, C.: The influence of mesoscale circulation systems on triggering convective cells over complex terrain, Atmos. Res., 81, 150-175, 2006. 
Barthlott, C., Burton, R., Kirshbaum, D., Hanley, K., Richard, E., Chaboureau, J.-P., Trentmann, J., Kern, B., Bauer, H.-S., Schwitalla, T., Keil, C., Seity, Y., Gadian, A., Blyth, A., Mobbs, S., Flamant, C., and Handwerker, J.: Initiation of deep convection at marginal instability in an ensemble of mesoscale models: a case-study from COPS, Q. J. Roy. Meteor. Soc., 137, 118-136, doi:10.1002/qj.707, 2011.

Bauer, H.-S., Weusthoff, T., Dorninger, M., Wulfmeyer, V., Schwitalla, T., Gorgas, T., Arpagaus, M., and Warrach-Sagi, K.: Predictive skill in the COPS region of a subset of models participating in D-PHASE, Q. J. Roy. Meteor. Soc., 137, 287-305, doi:10.1002/qj.715, 2011.

Bennett, L. J., Browning, K. A., Blyth, A. M., Parker, D. J., and Clark, P. A.: A review of the initiation of precipitating convection in the United Kingdom, Q. J. Roy. Meteor. Soc., 132, 1001-1020, doi:10.1256/qj.05.54, 2006.

Bennett, L. J., Blyth, A. M., Burton, R. R., Gadian, A. M., Weckwerth, T. M., Behrendt, A., Di Girolamo, P., Dorninger, M., Lock, S.-J., Smith, V. H., and Mobbs, S. D.: Initiation of convection over the Black Forest mountains during COPS IOP15a, Q. J. Roy. Meteor. Soc., 137, 176-189, doi:10.1002/qj.760, 2011.

Boutle, I. A., Eyre, J. E. J., and Lock, A. P.: Seamless stratocumulus simulation across the turbulent gray zone, Mon. Weather Rev., 142, 1655-1668, doi:10.1175/MWR-D-13-00229.1, 2014.

Bryan, G. H., Wyngaard, J. C., and Fritsch, J. M.: Resolution requirements for the simulation of deep moist convection, Mon. Weather Rev., 131, 2394-2416, doi:10.1175/15200493(2003)131<2394:RRFTSO>2.0.CO;2, 2003.

Byers, H. R. and Rodebush, H. R.: Causes of thunderstorms of the Florida peninsula, J. Meteorl., 5, 275-280, 1948.

Colle, B. A. and Mass, C. F.: The 5-9 February 1996 flooding event over the Pacific Northwest: sensitivity studies and evaluation of the MM5 precipitation forecasts, Mon. Weather Rev., 128, 593-617, doi:10.1175/15200493(2000)128<0593:TFFEOT>2.0.CO;2, 2000.

Cotton, W. R., Bryan, G. H., and van den Heever, S. C.: Storm and Cloud Dynamics, 2nd Edn. Academic Press, Amsterdam, the Netherlands, Heidelberg, Germany, 809 pp., 2011.

Crook, N. A.: Sensitivity of moist convection forced by boundary layer processes to low-level thermodynamic fields, Mon. Weather Rev., 124, 1767-1785, 1996.

Doms, G., Förstner, J., Heise, E., Herzog, H.-J., Mironov, D., Raschendorfer, M., Reinhardt, T., Ritter, B., Schrodin, R., Schulz, J.-P., and Vogel, G.: A description of the nonhydrostatic regional COSMO model, Part II: Physical parameterization, Deutscher Wetterdienst, Offenbach, Germany, 161 pp., available at: http://www.cosmo-model.org (last access: 26 May 2015), 2011.

Done, J., Davis, C., and Weisman, M.: The next generation of NWP: explicit forecasts of convection using the Weather Research and Forecasting (WRF) model, Atmos. Sci. Lett., 5, 110 117, doi:10.1002/asl.72, 2004.

Fiori, E., Parodi, A., and Siccardi, F.: Dealing with uncertainty: turbulent parameterizations and grid-spacing effects in numerical modelling of deep moist convective processes, Nat. Hazards Earth Syst. Sci., 9, 1871-1880, doi:10.5194/nhess-9-1871-2009, 2009.

Fiori, E., Parodi, A., and Siccardi, F.: Uncertainty in prediction of deep moist convective processes: turbulence parameterizations, microphysics and grid-scale effects, Atmos. Res., 100, 447-456, doi:10.1016/j.atmosres.2010.10.003, 2011.

Garcia-Carreras, L., Parker, D. J., and Marsham, J. H.: What is the mechanism for the modification of convective cloud distributions by land-surface induced flows?, J. Atmos. Sci., 68, 619-634, doi:10.1175/2010JAS3604.1, 2011.

Gibbs, J. A. and Fedorovich, E.: Comparison of convective boundary layer velocity spectra retrieved from large-eddy-simulation and weather research and forecasting model data, J. Appl. Meteorol. Clim., 53, 377-394, doi:10.1175/JAMC-D-13-033.1, 2014.

Green, B. W. and Zhang, F.: Numerical simulations of Hurricane Katrina (2005) in the turbulent gray zone, J. Adv. Model. Earth Syst., 7, 142-161, doi:10.1002/2014MS000399, 2015.

Hanley, K. E., Plant, R. S., Stein, T. H. M., Hogan, R. J., Nicol, J. C., Lean, H. W., Halliwell, C., and Clark, R. A.: Mixing length controls on high resolution simulations of convective storms, Q. J. Roy. Meteor. Soc., 141, 272-284, doi:10.1002/qj.2356, 2014.

Honnert, R., Masson, V., and Couvreux, F.: A diagnostic for evaluating the representation of turbulence in atmospheric models at the kilometric scale, J. Atmos. Sci., 68, 3112-3131, 2011.

Hoskins, B. J., Draghici, I., and Davies, H. C.: A new look at the omega-equation, Q. J. Roy. Meteor. Soc., 104, 31-38, 1978.

Jorgensen, D. P. and Weckwerth, T. M.: Forcing and organization of convective systems, in: Radar and Atmospheric Science: A Collection of Essays in Honor of David Atlas, edited by: Wakimoto, R. M. and Srivastava, R., American Meteorological Society, Boston, 75-103, 2003.

Kain, J. S., Weiss, S. J., Bright, D. R., Baldwin, M. E., Levit, J. J., Carbin, G. W., Schwartz, C. S., Weisman, M. L., Droegemeier, K. K., Weber, D. B., and Thomas, K. W.: Some practical considerations regarding horizontal resolution in the first generation of operational convection-allowing NWP, Weather Forecast., 23, 931-952, 2008.

Kalthoff, N., Adler, B., Wieser, A., Kohler, M., Träumner, K., Handwerker, J., Corsmeier, U., Khodayar, S., Lambert, D., Kopmann, A., Kunka, N., Dick, G., Ramatschi, M., Wickert, J., and Kottmeier, C.: KITcube - a mobile observation system for convection studies deployed during HyMeX, Meteorol. Z., 22, 633647, doi:10.1127/0941-2948/2013/0542, 2013.

Mellor, G. L. and Yamada, T.: A hierarchy of turbulence closure models for planetary boundary layers, J. Atmos. Sci., 31, 17911806, 1974.

Pearson, K. J., Lister, G. M. S., Birch, C. E., Allan, R. P., Hogan, R. J., and Woolnough, S. J.: Modelling the diurnal cycle of tropical convection across the "grey zone", Q. J. Roy. Meteor. Soc., 140, 491-499, doi:10.1002/qj.2145, 2014.

Petch, J. C., Brown, A. R., and Gray, M. E. B.: The impact of horizontal resolution on the simulations of convective development over land, Q. J. Roy. Meteor. Soc., 128, 2031-2044, doi:10.1256/003590002320603511, 2002.

Petrik, R.: Physical validation and bracket-based dynamical cores for mesoscale NWP models, PhD thesis, Reports on Earth System Science 121, ISSN 1614-1199, Hamburg, Germany, 163 pp., available at: http://www.mpimet.mpg.de/wissenschaft/ publikationen/berichte-erdsystemforschung.html (last access: 1 September 2015), 2012.

Roebber, P. J., Schultz, D. M., Colle, B. A., and Stensrud, D. J.: Towards improved prediction: high-resolution and ensemble mod- 
eling systems in operations, Weather Forecast., 19, 936-949, 2004.

Rögnvaldsson, O., Bao, J.-W., and Olafsson, H.: Sensitivity simulations of orographic precipitation with MM5 and comparison with observations in Iceland during the Reykjanes Experiment, Meteorol. Z., 16, 87-98, doi:10.1127/0941-2948/2007/0181, 2007.

Rossa, A., Bruen, M., Frühwald, D., Macpherson, B., Holleman, I., Michelson, D., and Michaelides, S.: Use of Radar Observations in Hydrological and NWP Models, COST 717 Final Report, available at: http://www.smhi.se/cost717/ (last access: 26 May 2015), 2005.

Schättler, U., Doms, G., and Schraff, C.: A description of the nonhydrostatic regional COSMO-model, Part VII: User's guide, Deutscher Wetterdienst, Offenbach, Germany, 200 pp., available at: http://www.cosmo-model.org (last access: 26 May 2015), 2013.

Schwartz, C. S., Kain, J. S., Weiss, S. J., Xue, M., Bright, D. R., Kong, F., Thomas, K. W., Levit, J. J., and Coniglio, M. C.: Nextday convection-allowing WRF model guidance: a second look at $2 \mathrm{~km}$ versus $4 \mathrm{~km}$ grid spacing, Mon. Weather Rev., 137, 33513372, doi:10.1175/2009MWR2924.1, 2009.

Skamarock, W. C.: Evaluating mesoscale NWP models using kinetic energy spectra, Mon. Weather Rev., 132, 3019-3032, doi:10.1175/MWR2830.1, 2004.

Talbot, C., Bou-Zeid, E., and Smith, J.: Nested mesoscale largeeddy simulations with WRF: performance in real test cases, J. Hydrometeorol., 13, 1421-1441, doi:10.1175/JHM-D-11-048.1, 2012.

Tiedtke, M.: A comprehensive mass flux scheme for cumulus parameterization in large-scale models, Mon. Weather Rev., 117, 1779-1800, 1989.

Trier, S. B.: Convective storms - convective initiation, in: Encyclopedia of Atmospheric Sciences, Vol. 2, edited by: Holton, J. R., Curry, J. A., and Pyle, J. A., Academic Press, London, 2003.
Verrelle, A., Ricard, D., and Lac, C.: Sensitivity of high-resolution idealized simulations of thunderstorms to horizontal resolution and turbulence parametrization, Q. J. Roy. Meteor. Soc., 141, 433-448, doi:10.1002/qj.2363, 2015.

Warren, R., Kirshbaum, D., Plant, R., and Lean, H.: A 'Boscastletype' quasi-stationary convective system over the UK Southwest Peninsula, Q. J. Roy. Meteor. Soc., 140, 240-257, doi:10.1002/qj.2124, 2014.

Weisman, M. L., Davis, C., Wang, W., Manning, K. W., and Klemp, J. B.: Experiences with 0-36 h explicit convective forecasts with the WRF-ARW model, Weather Forecast., 23, 407437, doi:10.1175/2007WAF2007005.1, 2008.

Wicker, L. J. and Skamarock, W. C.: Time-splitting methods for elastic models using forward time schemes, Mon. Weather Rev., 130, 2088-2097, 2002.

Wilson, J. and Schreiber, W.: Initiation of convective storms at radar-observed boundary-layer convergence lines, Mon. Weather Rev., 114, 2516-2536, 1986.

Wyngaard, J. C.: Toward numerical modeling in the "Terra Incognita”, J. Atmos. Sci., 61, 1816-1826, 2004.

Zängl, G.: To what extent does increased model resolution improve simulated precipitation fields? A case study of two north-Alpine heavy-rainfall events, Meteorol. Z., 16, 571-580, doi:10.1127/0941-2948/2007/0237, 2007.

Zängl, G., Reinert, D., Rípodas, P., and Baldauf, M.: The ICON (ICOsahedral Non-hydrostatic) modelling framework of DWD and MPI-M: description of the non-hydrostatic dynamical core, Q. J. Roy. Meteor. Soc., 141, 563-579, doi:10.1002/qj.2378, 2015. 